
ENPAEERIMG LIBRARY

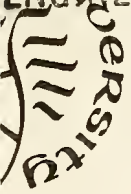

RIES

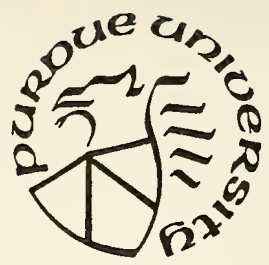

LIBRARIES

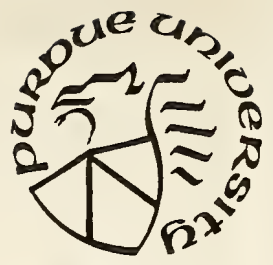

LIBRARIES
S키방

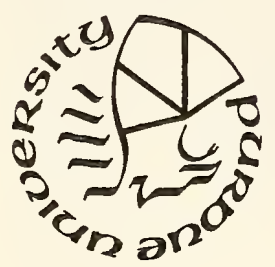

$\sqrt{\frac{\pi}{2} \pi^{\infty}}$

ARIES

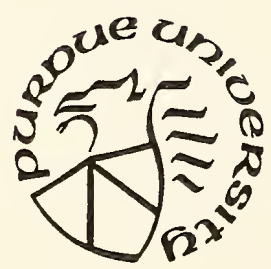

LIBRARIES
S캅ำ

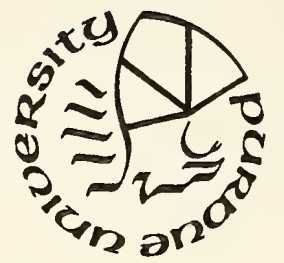

S $\exists I y \forall$

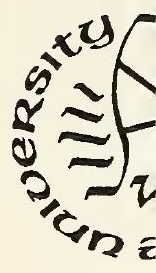

S카직

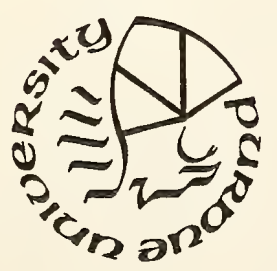

$f$

ARIES

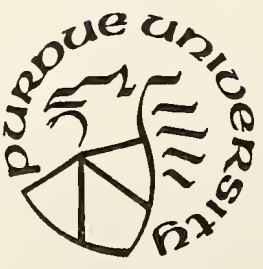

LIBRARIES

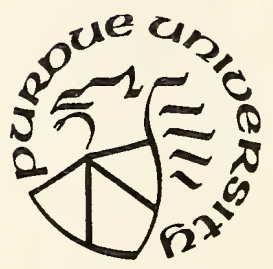

LIBRARIES

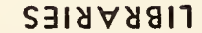

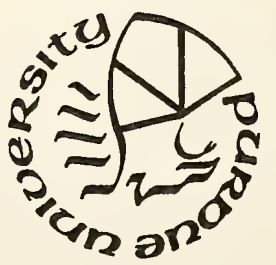

S카

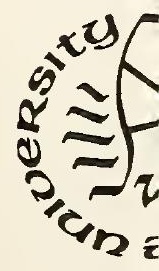

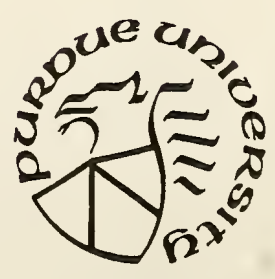

LIBRARIES 


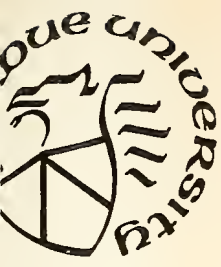

LIBRARIES

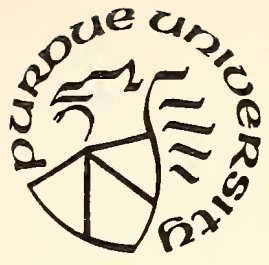

LIBRARIES

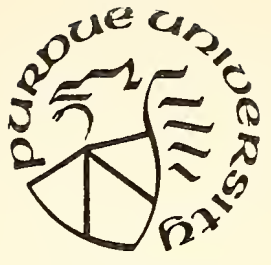

LIBRARIES
S키박

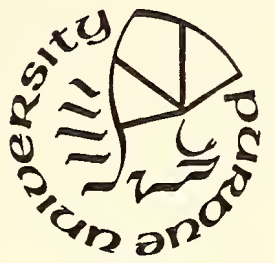

S키방า

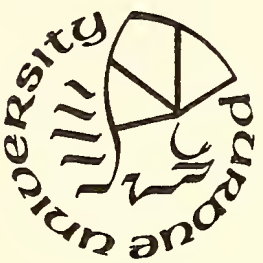

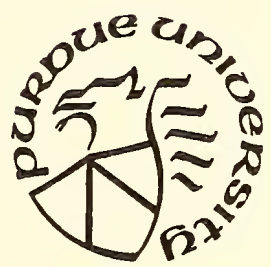

LIBRARIES

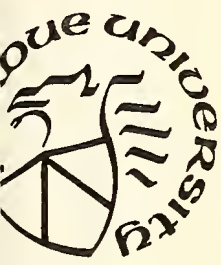

LIBRARIES
S키밤ำ

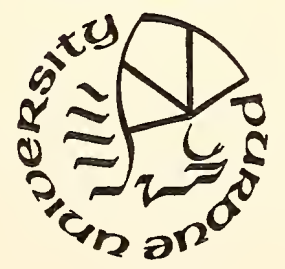

ร캅ำ

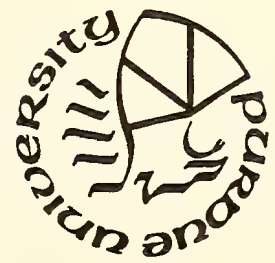

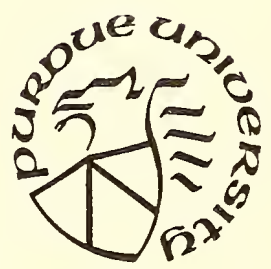

LIBRARIES

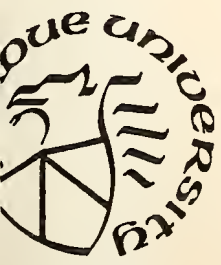

LIBRARIES

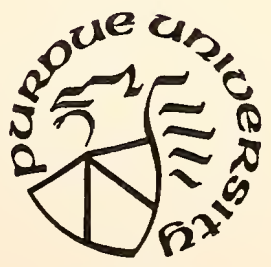

LIBRARIES

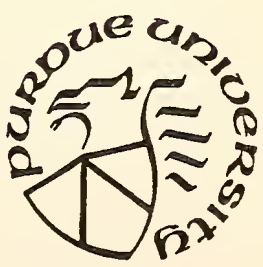

LIBRARIES 
SCHOOL OF CIVIL ENGINEERING

0.51

7 te

JOINT HIGHWAY

RESEARCH PROJECT JHRP-76-28

AN EXAMINATION OF THE

VARIABILITY RESULTING FROM SOIL COMPACTION

Martin F. Essigman, Jr.
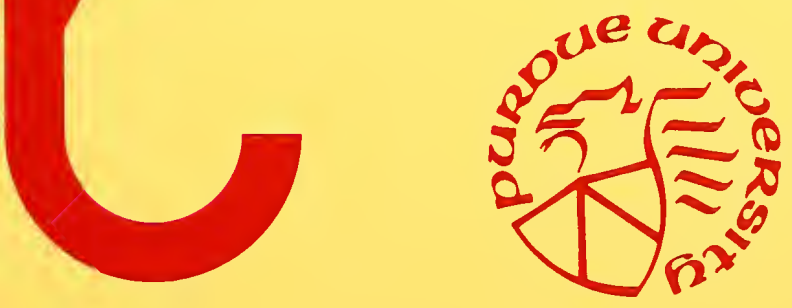

PURDUE UNIVERSITY

JDIANA STATE HIGHWAY COMMISSION 

T0: J. F. McLaughlin, Director Joint Highway Research Project

FROM: H. L. Michael, Associate Director Joint Highway Research Project
October 5,1976

Project: $\quad C-36-5 M$

File: $6-6-13$

The attached Interim Report titled "An Examination of the Variability Resulting from Soil Compaction" has been authored by Mr. Martin F. Essigman, Jr., Graduate Instructor in Research on our staff, under the direction of Professor A. G. Altschaeffl of the Geotechnical Engineering area and Principal Investigator on the Study. The Report is the second on this Study, "Improving Embankment Design and Performance".

As the title indicates, this Report concerns the variability found in compaction of soils. The findings reported utilized laboratory compaction with some correlation with field compaction. A prediction technique has been developed which permits the designer to specify the technique of compaction to be used based on the compaction variability he can accept. Further correlation of laboratory and field compaction functions is in process as is demonstration of use of the prediction techniques under field conditions.

The Report is presented for acceptance as partial fulfillment of the objectives of the Study. It will also be forwarded to ISHC and FHWA for review and acceptance.

Respectfully submitted,

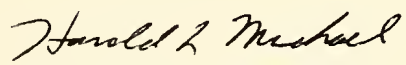

Harold L. Michael

Associate Director

HLM : ms
CC: W. L. Dolch
M. L. Hayes
C. F. Scholer
R. L. Eskew
K. R. Hoover
M. B. Scott
G. D. Gibson
G. A. Leonards
W. H. Goetz
C. W. Lovell
K. C. Sinha
M. J. Gutzwiller
R. D. Miles
L. E. Wood
G. K. Hallock
P. L. Owens
E. J. Yoder
D. E. Hancher
G. T. Satterly
S. R. Yoder 
Digitized by the Internet Archive in 2011 with funding from

LYRASIS members and Sloan Foundation; Indiana Department of Transportation 
Interim Report

AN EXAMINATION OF THE VARIABILITY RESULTING

FROM SOIL COMPACTION

\author{
by \\ Martin F. Essigman, Jr. \\ Graduate Instructor in Research \\ Joint Highway Research Project \\ Project No.: C-36-5M \\ File No.: 6-6-13 \\ Prepared as Part of an Investigation \\ Conducted by \\ Joint Highway Research Project \\ Engineering Experiment Station \\ Purdue University \\ in cooperation with the \\ Indiana State Highway Commission \\ and the \\ U.S. Department of Transportation \\ Federal Highway Administration
}

The contents of this report reflect the views of the author who is responsible for the facts and the accuracy of the data presented herein. The contents do not necessarily reflect the official views or policies of the Federal Highway Administration. This report does not constitute a standard, specification, or regulation. 
TECHNICAL REPORT STANDARD TITLE PAGE

\begin{tabular}{|c|c|}
\hline $\begin{array}{l}\text { 1. Roport No. } \\
\text { JHRP }-76-28\end{array}$ & 3. Recipient's Cotolog No. \\
\hline \multirow{2}{*}{$\begin{array}{l}\text { 4. Titlo ond Subrito } \\
\text { An Examination of the Variability } \\
\text { Resulting from Soil Compaction }\end{array}$} & \multirow{2}{*}{$\begin{array}{l}\text { 5. Roport Doto } \\
\text { October } 1976 \\
\text { 6. Porfarming Orgonization Codo }\end{array}$} \\
\hline & \\
\hline $\begin{array}{l}\text { 7. Author(s) } \\
\text { Martin F. Essigman, Jr. }\end{array}$ & $\begin{array}{l}\text { 8. Porforming Orgonization Roport No. } \\
\text { JHRP }-76-28\end{array}$ \\
\hline \multirow{3}{*}{$\begin{array}{l}\text { 9. Porforming Organizotion Nome and Address } \\
\text { Joint Highway Research Project } \\
\text { Civi Engineering Building } \\
\text { Purdue University } \\
\text { W. Lafayette, Indiana } 47907\end{array}$} & \multirow{3}{*}{$\begin{array}{l}\text { 10. Wark Unit No. } \\
\begin{array}{l}\text { 11. Controct or Grant No. } \\
\text { HPR-1 ( } 14) \text { Part I I } \\
\text { 1.3. Typo of Roport ond Period Covered }\end{array}\end{array}$} \\
\hline & \\
\hline & \\
\hline \multirow{2}{*}{$\begin{array}{l}\text { 12. Sponsoring Agency Nome and Addrese } \\
\text { Indiana State Highway Commission } \\
\text { State Office Building } \\
100 \text { North Senate Avenue } \\
\text { Indianapolis, Indiana } 46204\end{array}$} & Interim Report \\
\hline & 14. Sponsoring Agency Code \\
\hline
\end{tabular}

15. Supplomentory Notes

Prepared in cooperation with the U.S. Dept. of Transportation,

Federal Highway Administration.

From the study, "Improving Embankment Design and Performance"

16. Abstroct

A glacial silty clay was studied to determine what variables control laboratory impact-compacted density and strength and their variabilities. Additionally, the laboratory data were examined statistically as possible predictors of field results.

Density and strength are controlled by moisture content and density, respectively, as well as by interactions between variables (i.e. one-on-one relations between variables are not adequate to define the dependences). The variabilities are controlled by the magnitudes of density or strength as well as by interactions between variables.

Results of limited field sheepsfoot compaction of the same soil show relationships very similar to those from the laboratory; the field variabilities are, however larger. Enough field data were not available to develop reliable field compaction relationships. However a prediction technique was developed, using laboratory data that shouldultimately be applicable for field data. The designer selects the strength he wishes for the compacted soil, and the variability he will accept; the technique tells him what density, moisture content, and energy to specify for compaction of that soil using a specific type of compaction. Appropriate field data are now being collected to demonstrate this technique for field compaction predictions.

17. Koy Words Compaction; compressive strength; dry density; field; field property prediction; laboratory; soil, soil property variability; statistical analysis
18. Distribution Stotement

No restrictions. This document is available to the public through the National Technical Information Service, Springfield, VA 22161.

19

9. Security Clonsif, (of this report)

20. Securliy Clossif. (of this page)

Unclassified

Unclassified

22. Price 
TABLE OF CONTPNTS

Page

IIST OF TABIES........................

IIST OF FIGURES.......................vii

I.IST OF SYMBOLS AND ABBRIVIATIONS.............

HIGHLIGHT SUMMARY $\ldots \ldots \ldots \ldots \ldots \ldots \ldots \ldots \ldots \ldots \ldots \ldots$

INTRODUCTION.............................

REVIEW OF THS ITTERATURE....................4

Comparison of Field and Laboratory

Compaction Characteristics.................4

Non-Random Compaction Variability.............8

Random Compaction Variability...............14

Structure of Compacted Clays................22

EXPERIMENTAL PROCEDURES...................26

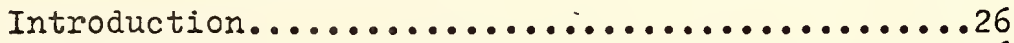

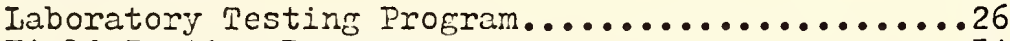

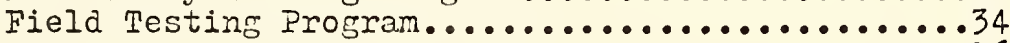

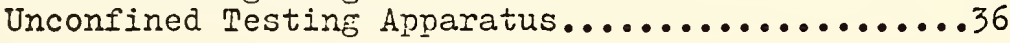

ANAIYSIS OF EXPERIIENTAL RESULTS ..............41

Statistical Analysis....................41

Statistical Results.....................47

DISCUSSION OF RESULTS .........................

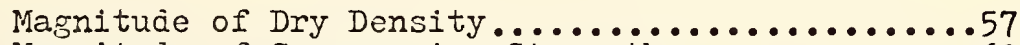

Nagnitude of Compressive Strength............62

Magnitude of Dry Density Variability.............69

Magnitude of Compressive Strength

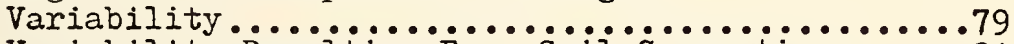

Variability Resulting From Soil Compaction........ 84 
TABLE OF CONTENTS, cont.

'Page

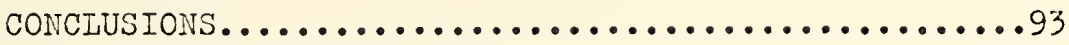

RECORINENDATIONS FOR FURTHER STUDIES............95

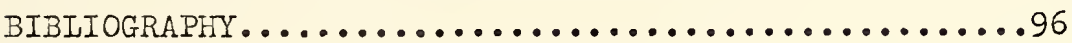

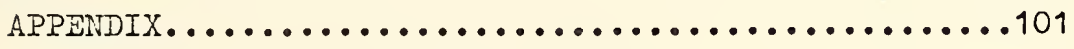


LIST OF TABIES

Table

Page

1. Effect of Soil Homogeneity on

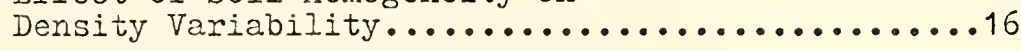

2. Effect of Compaction Equipment on Density Variability.....................20

3. Identification Test Results..................

4. Iaboratory Compaction Specifications...........29

5. Statistical Models Used for Analysis...........48

6. Significant All-Possible Regression Models

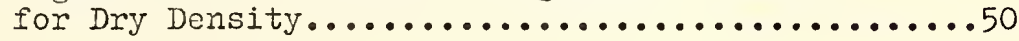

7. Significant All-Possible Regression Models for Variation in Dry Density................51

8. Significant All-Possible Regression Models for Unconfined Strength..................52

9. Significant All-Possible Regression Models for Variation in Unconfined Strength...........53

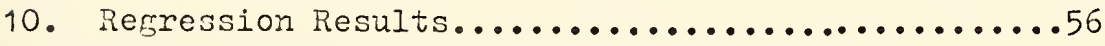

11. Explanation of Identification Numbers for Appendix Data............................101

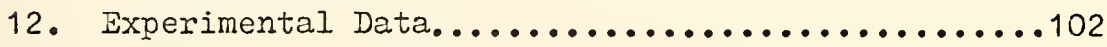


IIST OF FIGURES

Figure

Page

1. Grain Size Distribution..................28

2. Method of Obtaining Strength Samples

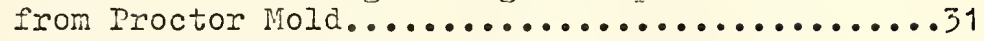

3. Strength and Water Content Changes as a Function of Storage Time...................33

4. Field Drive Tube Sampling Apparatus...........37

5. Unconfined Testing Apparatus.....................

6. Typical Stress-Strain Curves...............40

7. Regression Terminology..................43

8. Moisture-Density Relationships for

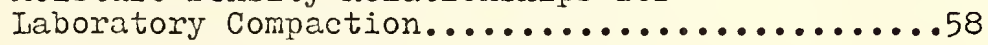

9. Comparison of Standard Proctor and Harvard Miniature Moisture-Density Relationships........................60

10. Comparison of Hoisture-Density Rclationships for Field and Laboratory

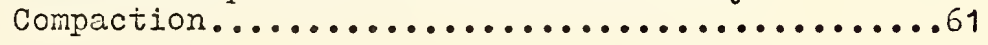

11. Moisture-Strength Relationships for Laboratory Compaction..................63

12. Comparison of Standard Proctor and Harvard Piniature Noisture-Strength Results ....65

13. Comparison of Moisture- Strength Relationships for Field and Laboratory Compaction..........67

14. Comparison of lieasured and Predicted Field Strengths...........................68 
IIST OF FIGURES, cont.

Figure

Page

15. Moisture-Variation in Density Relationships for Laboratory Comnaction.................70

16. Comparison of Standard Proctor and Harvard Miniature Variation in Density-Noisture

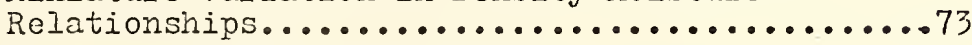

17. Comparison of Moisture-Variation in Dry Density for Field and Laboratory

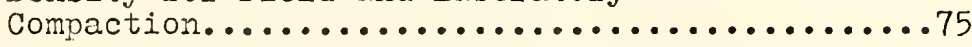

18. Noisture-Variation in Density Relationship from Published Data...................77

19. Moisture-Variation in Density Relationship for ISHC Contract 8757 (Reference 29).........78

20. Moisture-Variation in Strength Relationships for Lavoratory Compaction................81

21. Comparison of Standard Proctor and Harvard Miniature Moisture-Variation in

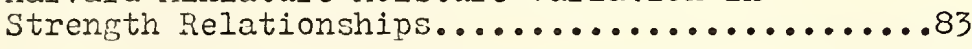

22. Comparison of Moisture-Variation in Strength Relationship for Field and

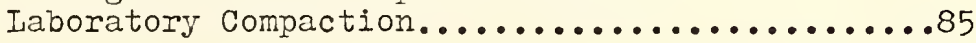

23. Coefficient of Variation of Strength for Laboratory and Field Compaction..........86

24. Nomograph for Strength and Strength

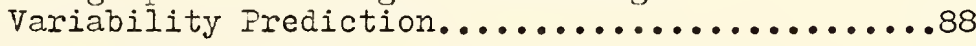

25. Acceptable Moisture-Density Regions for Desired Strength and Strength Variability......90 
LIST OF SYMBOLS AND ABBREVIATIONS

\begin{tabular}{|c|c|}
\hline $\mathrm{v}$ & Moisture Content (\%) \\
\hline$\gamma_{\mathrm{a}}$ & Dry Density (pcf) \\
\hline$q_{u}$ & Unconfined Compressive Strength (psi) \\
\hline$\vec{w}$ & Nean Hoisture Content within Statistical Subset \\
\hline $\bar{\gamma}_{\alpha}$ & Mean Dry Density within Statistical Subset \\
\hline$\overline{\mathrm{q}}_{\mathrm{u}}$ & $\begin{array}{l}\text { Iean Unconfined Strength within Statistical } \\
\text { Subset }\end{array}$ \\
\hline$S(w)$ & $\begin{array}{l}\text { Standard Deviation of Moisture Content within } \\
\text { Statistical Subset }\end{array}$ \\
\hline$s\left(\gamma_{d}\right)$ & $\begin{array}{l}\text { Standard Deviation of Dry Density within } \\
\text { Statistical Subset }\end{array}$ \\
\hline$s\left(q_{u}\right)$ & $\begin{array}{l}\text { Standard Deviation of Unconfined Strength } \\
\text { within Statistical Subset }\end{array}$ \\
\hline $\mathrm{RC}$ & $\begin{array}{l}\text { Relative Compaction; Ratio of Dry Density to } \\
\text { Maximum Dry Density; Expressed as a } \%\end{array}$ \\
\hline$N$ & Number of Items in a Sample \\
\hline $\mathrm{E}$ & Energy Ratio \\
\hline AASHO & American Association of State Highway Officials \\
\hline ASCE & American Society of Civil Engineers \\
\hline ASTM & American Society for Testing and Naterials \\
\hline ISHC & Indiana State Highway Commission \\
\hline SPSS & $\begin{array}{l}\text { Statistical Paclage for the Social Sciences; a } \\
\text { system of statistical library programs, on file } \\
\text { in the Purdue University computer system }\end{array}$ \\
\hline
\end{tabular}




\section{HIGHLIGHT SUMMARY}

This is the second report from this project. The objectives of the project involve the variability and the source of variability of the strength of field compacted earth. Ultimately, the prediction of the properties of the field mass from laboratory data is desired.

Laboratory test data were generated by impact compaction for a glacial silty clay. The compacted density was found to be controlled by the moisture content and an interaction between moisture content and energy. The strength was controlled by the density and an interaction of density with moisture content.

The variability in density was controlled by moisture content, density magnitude, and interactions of moisture content with energy and with density. The variability in strength was controlled by the strength magnitude and the variability in density.

Simple one-on-one relationships are found to be inadequate to properly define how the properties are controlled by the variables.

Limited field sheepsfoot compaction results on the same soil produced relationships similar to those of the laboratory data. The variabilities were, however, larger. Enough field data are not yet available to relate laboratory compaction functions to these for field compaction. Even so, a prediction 
technique has been developed based upon laboratory data. The designer selects the strength he wishes for the compacted soil, and the variability he is willing to accept; the technique will tell him the density, moisture content, and energy to specify for compaction of that soil using a specific type of compaction. Appropriate field data are now being collected to demonstrate this technique for field rolling, and to correlate the laboratory and field compaction functions. 


\section{INTRODUCPION}

Soil compaction may be defined as a mechanical densification process which produces a reduction of the air voids within the earthen material at a relatively unchanged moisture content. This densification is carried out to improve the engineering properties of the soil mass and, hence, improve the performance of the material for a given application. One of the most difficult questions to answer concerning this process is the type and level of compaction which should be specified for a given project. This type and level of compaction should depend on the engineering properties required to insure the acceptable performance of the finished structure. Therefore, the compaction specification should be based upon the desired engineering properties and the intended use of the earthen structure. Presently, when the design engineer prepares an end result compaction specification for a particular project, he specifies a minimum percentage compaction to be achieved during the field compaction process; often an acceptable range in moisture contents is also noted. This percentage compaction is usually expressed in terms 
of the maximum achieved in the laboratory using some standard compaction procedure. The field density and moisture measurements, performed for quality control purposes, are then translated into an efficiency of the compaction process.

The engineering behavior of the field compacted soils is often left to inference from test results obtained on soils compacted in the laboratory. This use of laboratory results to predict field performance may not be the most desirable situation, but the engineer is forcea into it because of the time and expense involved in conducting any kind of field study on the behavior of compacted soils. Such inferred field performance leaves much uncertainty because it neglects the inherent differences between the field and laboratory compaction processes, as well as the variability associated with each process. Part of the variability in the field arises from the fact that the soils, and the construction process which compacts them, are in themselves variable. Therefore, the resultant soil mass is non-uniform. Differences in properties result from differences in the construction process, inspection process, testing process and the analyses of the tests performed. A difference in any of these factors, with all the others held constant, will result in changes in variability within the compacted mass. 
It is the intent of this research to examine the feasibility of establishing a more rational method of predicting field performance from laboratory tests. It attempts to develope laboratory relationships which would allow a prediction of the behavior parameters in the field product. It will also recognize, and attempt to allow for, the inherent variability wich will exist in the compacted product as a function of the soil type, method of compaction, moisture content and compaction energy. The relative importance of the compaction variables in controlling the variability in dry density and shear strength will also be examined. It does not attempt to modify the present compaction specification format that seems to be so well engrained in present practice. The relationships developed in the laboratory will then be compared to field compaction results to test their usefulness as predictors of field performance. 
REVIEW OF THE IITERATURE

\section{Comnarison of Field and Iaboratory}

\section{Compaction Characteristics}

The benefits derived from soil compaction have been recognized since the earliest of times. One of the earliest references to soil compaction appears in the writings of the Chinese engineer Chia Shan (178 B.C.) who wrote, in the Chih Yen, about the use of metal rammers to improve the wearing characteristics of a road surface (Ingles, 1974). However, it has only been within recent history that the level of densification required in the field has been based upon any laboratory determination. Proctor (1933) described a laboratory test procedure for determining the optimum moisture content and maximum dry density obtainable for a soil for a California earthen dam with an energy approximating that of field equipment at that time. The method outlined by Proctor is basically still in use today, and serves as a basis for most present end result compaction specifications.

Ideally, the compaction method used in the laboratory should yield a moisture-density relationship that 
closely approximates that produced by the field compaction equipment. Large scale field compaction studies reported by the Roads Research Laboratory (1961), Hilf (1959), and the Waterways Experiment Station (1949), show that no laboratory compaction method in use today duplicates the effects of various field compaction equipment. These reports show that the lines of optimums for the field and laboratory compaction did not coincide and that the relative position of the lines of optimuns with respect to the line of saturation (zero air voids) varied erratically with respect to soil type and compaction equipment. This indicates that the efforts applied in the laboratory and field do not yield the same functional relationship with respect to the density obtained.

Generally, the comparison of field and laboratory shear strength characteristics is inferred from test results from laboratory compacted specimens at the same moisture content and dry density as in the field. If the moisture and density are the principal factors controlling the shear strength of the field compacted soil, then a reasonable comparison between these results should be available. However, since the compaction method also has an influence on the fabric of the soil which, in turn, has an influence on the shear strength for a given water content and dry density, mere 
similarity in the laboratory and field water content versus dry density relationship cannot always imply a similarity in strength. It must be concluded, therefore, that specirications in terms of relative compaction alone may not be sufficient to insure a knowledge of the shear strength of a compacted cohesive soil in the field. This is so even when the field shear strength is based upon laboratory tests for samples compacted at similar water contents to the required dry density.

Holtz and Fllis (1964) report shear strength data from three Bureau of Reclamation dams. The dams were compacted using the Bureau's heavy sheepsfoot roller. Laboratory triaxial tests were run on undisturbed field samples and remolded impact and laboratory sheepsfoot samples. Their results show that the laboratory impact specimens produced strength results similar to those obtained from the field undisturbed samples. The differences observed were felt by the authors to be "within the range of experimental error."

Peterson (1975) presents compaction data from an embankment being constructed by the ISHC. The data presented were for a brown, silty clay, compacted by a tamping foot roller. Undisturbed samples of the field compacted soils were obtained using a 
drive tube sampler, and tested in unconfined compression. The same soil type was compacted in the laboratory (Standard Proctor energy) and tested in unconfined compression. Regression equations were then developed to explain the laboratory strength relationships. It was found that the magnitude of the unconfined strength for the laboratory compacted samples was a function of the dry density and the third order moisture content $\left(w^{3}\right)$. The magnitude of the dry density for the laboratory compacted soil was found to be a function of second and third order $\left(w^{2}\right.$ and $w^{3}$ ) moisture content. These laboratory relationships were then statistically tested as predictors of field performance. Peterson noted that the predictions produced were quite reasonable and statistically valid.

For this study, experiments will be done in the laboratory to find the functional relationship between moisture, density and strength. This functional relationship will be arrived at by statistical analysis of the experimental data, and it will be tested as a predictor of field characteristics. 


\section{Non-Random Compaction Variability}

In the preparation of a section of earthen embankment, the construction and inspection process forms a complex system of sources of uncertainty. Each element in this system contributes to variations in the properties used to insure the quality and subsequent future performance of the structure. In practice, it is uneconomical, or impossible, to control all these elements precisely. Therefore, since one must put up with them, they may be considered as allowable, or random variations. In contrast to the random variations are those which result from preventable or controllable variations; these may be considered as non-random variations. Turnbull et al. (1966) listed the source of some of these non-random variations as:

1) changes in soil type from the borrow area;

2) changes in operation such as moisture content adjustment, mixing, non-uniform loading, and placement methods;

3) changes in operation on the fill, such as number and type of hauling, spreading and compaction equipment;

4) changes in lift thicknesses;

5) changes in environmental factors, such as temperature, drought, rain; 
6) changes in human and equipment factors in the testing program.

Most of these non-random variations also affect the results of the laboratory compaction process. Additional non-random laboratory variations, which are easier to consistently control, result from:

1) changes in the compaction process;

2) changes in the size and shape of the compaction mold, as well as the support for the mold;

3) changes in sample preparation.

If It were possible to control exactly all the non-random variations, then the random variations would produce results which could be represented by a preestablished distribution. If the measured results are free of any biasing influence, then this distribution can be characterized by two quantities: the mean and the standard deviation. The standard deviation is the universally accepted measure of variability. The higher the standard deviation of a set of results, the larger the spread in data.

The existence of these variations in embankment compaction have been recognized for many years, although many engineers are not strongly concerned with the extent of variability. The ideal situation for the design engineer would be the ability to quantify the 
extent of the variability present in the compacted mass, and its sources, and then krow how this variability will affect otiner performance properties. Each of the non-random variables affects the compaction variability in a different manner.

It has been well established that for a fiven compaction method and compactive effort, it is the soil type wich usually determines the maximum dry density and optimum moisture content. The grain size distribution, clayeyness and water content, are the main characteristics which determine the response of a soil to a given compactive effort. As the soil becomes more sranular and better graded, the maximum dry density under given conditions of placement will increase because of the better particle packing arrangement which is possible. 1

For compaction in the field, the type and distribution of the compactive effort will affect the maximum dry density and optimum moisture content. Sheepsfoot, rubber tired and vibratory rollers each have a different type of compactive action and each of these types of action has a significant influence on properties other than density; e.g. shear strength and swelling characteristics. The distribution of compactive effort varies

1. A "well graded" soil is often defined as one which exists or can be placed at a high density. 
with the percent of the total energy applied in each anplication of the compactive effort, and can have a significant efiect on the maximum dry density and optimum moisture content. Sowers and Kennedy (1954) found that the most important factor influencing the effectiveness of compaction, in the laboratory or in the field, was the percentage of the total energy applied in each application of the pressure. Their results showed that the greater the number of applications required to apply a certain amount of effort; the smaller the resultant unit weight. Therefore, within the limits of a given amount of effort, the greater compaction results when that effort is exerted in a single application. The results obtained in the field are also affected by the variability in lift thiclmess. Because of a decrease in pressure intensity with depth, the resultant dry density will also decrease (Johnson and Sallberg, 1960). Bruzelius (1954) conducted studies in sweden on a silty clay, a sandy silt, and a medium sand. The soil was compacted in 30 inch lifts with 6 passes of a 15.5 ton mubber tire roller. All three soils showed comparable densities at the surface, but the silty clay showed a drastic decrease in density with depth, while the medium sand showed little decrease in density. Therefore, the higher the soils intrinsic plasticity, or clayeyness, the less efficient will be the compaction with depth. 
The degree of compaction can also be changed by weather (climactic) conditions. The temperature of the soil and regional moisture will drastically affect the resulting maximum ary density. Compaction research has shown that increasing the compaction temperature will increase the maximum dry density and decrease the optimum moisture content. Iowering the compaction temperature is felt to make the water more viscous and thereby reducing the workability of the soil (Johnson and Sallberg, 1962). For several different soil types, decreases in maximum dry density of 2.0 - 3.6 pef have been reported by Hogentogler and Willis (1936) for a temperature change from $115^{\circ}$ to $35^{\circ} \mathrm{F}$; for a silty clay, changes in dry density of 10.5 pcf have been reported (Belcher, 1941) for a change in temperature of $40^{\circ} \mathrm{F}$; for a sandy clay, Highter (1969) reports changes of 5.0 pcf in dry density for a change of $50^{\circ} \mathrm{F}$.

The changes in shear strength that are produced as a function of changes in dry density can be determined by using several different compaction energies and comparing the produced strengths at a constant value of moulding water content. This process assumes that there is no effect of possible changes in soil structure as the optimum water content decreases with increasing compaction energy. This assumption should be valid if the strength is measured at strains large enough to 
mobilize the strength; however, if the strength is measured at low strains, the influence of differences in soil structure should not be neglected. In considering the influence of dry density on shear strength it is also necessary to make a distinction between soaked and as compacted strengths.

Seed and Monismith (1954), Seed, Mitchell and Chan (1960) and Casagrande and Hirschfeld (1962) all have presented data on the relationship between dry density and shear strength at different moulding water contents. AIl these data indicate that an increase in dry density will cause an increase in shear strength for a given water content, provided the shear strength is defined at both large strains and moderate confining pressure. In general, the rate of increase in shear strength with an increase in dry density is largest for the lowest value of water content. As the moulding water content increases, the increase in shear strength is small to nonexistent, depending on the soil being investigated.

In this study, an effort will be made to control those non-random variables which can be easily controlled, or at least held at a constant level. It is recognized that if these variables are not controlled the resultant mass will not have a uniform density, and therefore, will not have a uniform and predictable strength. By removing most of this non-random variation, it is hoped 
that quantification of the magnitude and sources of the random variations will be possible.

\section{Random Compaction Variability}

A certain amount of variability in the compacted properties of an embankment should be expected for even the most uniform soil borrow sources, and strictly controlled operations. Carey (1957) reported the variability in densities for 300 samples taken from 59 borings, in a grid pattern, covering the borrow arca for the AASHO Road Test project. Laboratory Standard Proctor tests were run on each sample, and results showed that, even though the material appeared to be highly uniform, the maximum dry unit weights ranged from 110.0 to 126.0 per (mean of 117.2 pcf). This mean value was established for compaction control purposes. Analysis of the construction control data for this same project revealed that two density determinations, made by drive tubes within several inches of each other, often differed by 2-3 pcf. There was an even greater amount of variation if points were considered over a larger area. That is, the variability between lifts or sections of the project was larger than the variation within a small section of the lift.

Other investigators have reported similar results. Fischer, et al. (1962) present data for a residual, red, 
silty clay. They performed numerous control tests over various size test areas, using a nuclear gage. Within the smallest test section considered ( $5 \mathrm{sq}$. ft. of surface area), they report standard deviations in dry density and moisture content of $2.8 \mathrm{pcf}$ and $0.14 \%$, respectively. For the largest area considered (6400 sq. It.), they report 9.7 pcf and 2.9\% standard deviations for dry density and moisture content respectively. Regarding this problem of scatter in measured densities, in a test fill constructed in conjunction with the Mica Dasn (Hillis \& Smith, 1967) it was found necessary to measure at least ten densities on each test strip, with each density hole having a volume of about $5 \mathrm{cu}$. ft. in order to overridethe large variation in density over the strip and thus obtain a significant value for the average density. While this may be a drastic example, it does indicate the measures which may be necessary to entirely remove the large field variations experienced.

Evidence indicates that the variability in density is a function of the heterogeneity of the soil. Sherman, et al. (1967), Smith and Prystock (1966), Jorgenson (1969) and Williassson (1969) all report variations in measured densities in relationship to the soil homogeneity. Their results are shown in Table 1. Hence, the use of statistical distributions should not be used to compare the "quality of the work" from one site to another unless all other 


\section{TABLE 1}

Effect of Soil Homogeneity on Density Variability

\begin{tabular}{|c|c|c|c|c|}
\hline \multirow[b]{2}{*}{ REFERENCE } & \multirow[b]{2}{*}{$\begin{array}{l}\text { SOII } \\
\text { TYPS }\end{array}$} & \multicolumn{3}{|c|}{ DRY DENSITY } \\
\hline & & $N$ & $\begin{array}{l}\text { MEAN } \\
(\% \mathrm{RC})\end{array}$ & $\begin{array}{c}\text { SRD } \\
\text { DEV } \\
(\% R C) \\
\end{array}$ \\
\hline \multirow{3}{*}{$\begin{array}{l}\text { Sherman, } \\
\text { et al. } \\
\quad(1967)\end{array}$} & $\begin{array}{l}\text { clayey silty sand, } \\
\text { medium plasticity, } \\
\text { homogeneous }\end{array}$ & 50 & 92.9 & 2.4 \\
\hline & $\begin{array}{l}\text { clayey silty sand, } \\
\text { boulders to } 6 ", \\
\text { heterogeneous }\end{array}$ & 50 & 90.5 & 3.1 \\
\hline & $\begin{array}{l}\text { heavy clay, sand, } \\
\text { stone, shale, very } \\
\text { heterófeneous }\end{array}$ & 44 & 93.6 & 5.5 \\
\hline \multirow{3}{*}{$\begin{array}{l}\text { Jorgenson } \\
\quad(1969)\end{array}$} & Glaciated soil area & 100 & 88.7 & $4 \cdot 5$ \\
\hline & end moraine area & 98 & 89.9 & 8.04 \\
\hline & non-flaciated area & 54 & 97.8 & 4.8 \\
\hline \multirow{3}{*}{$\begin{array}{l}\text { Williamson } \\
(1969)\end{array}$} & $\begin{array}{l}\text { silt to silty clays, } \\
\text { low plasticity, } \\
\text { homogeneous }\end{array}$ & 200 & 92.4 & 5.76 \\
\hline & $\begin{array}{l}\text { low plasticity silt, } \\
\text { to moderately plastic } \\
\text { clays, heterogeneous }\end{array}$ & 140 & 95.5 & 6.02 \\
\hline & $\begin{array}{l}\text { highly plastic clayey } \\
\text { sand, very } \\
\text { heterogencous }\end{array}$ & 138 & 96.1 & 6.33 \\
\hline \multirow{3}{*}{$\begin{array}{l}\text { Smith and } \\
\text { Prystock } \\
\quad(1966)\end{array}$} & $\begin{array}{l}\text { uniform material, none } \\
\text { greater than } 3 / 4 "\end{array}$ & 200 & 92.86 & 2.44 \\
\hline & $\begin{array}{l}\text { fairly uniform material } \\
\text { greater than } 3 / 4 " \text { to } \\
\text { occasional } 6 " \text { ". }\end{array}$ & 200 & 90.54 & 3.09 \\
\hline & $\begin{array}{l}\text { extremely } \\
\text { heterogeneous }\end{array}$ & 176 & 93.64 & 5.52 \\
\hline
\end{tabular}


conditions are the same. Equal operational control may be maintained on two similar projects, but the resultant dispersions may be due to the material alone.

It should perhaps be noted that the standard deviations reported are actually the resultant of several components. If the reported deviations are interpreted as total standard deviations, $S_{\text {to }}$, then it can be assumed to consist of the following components:

1) Standard deviation component due to sampling, $S_{S}$;

2) Standard deviation component due to variations inherent in the material and compaction process, $\mathrm{S}_{\mathrm{c}}$;

3) Standard deviation component due to testing, $S_{t}$. The total deviation is then (after Wahls, et al., 1966)

$$
s_{\text {to }}=\sqrt{s_{s}^{2}+s_{c}^{2}+s_{t}^{2}}
$$

It is highly unlikely that each of these components could be evaluated for a specific portion of a field project, and thus determine the total standard deviation. Hoever, Ingles (1972) has reported results of laboratory testing where analysis of variance techniques have been used to separate some of these variability components. His conclusions show that the testing component of variance is almost identically equal with the sampling component of variance; hence, even with the most competent sampling, test variability will remain high. 
Therefore, many determinations will be required if the true mean and standard deviation are to be estimated with sufficient confidence.

The resultant scatter can also be related to the moisture level at which the compaction takes place. Johnson (1969) reports results obtained when several laboratories were given "identical" samples of $\mathrm{NL}$, CL and $\mathrm{CH}$ soils on which to perform compaction (at Standard Proctor energy) and strength tests. It was noted that the compaction results from the several laboratories compared well for all three soils at high degrees of saturation, the range being about 2 pcf for the lif and CI soils, and about 3 pcf for the $\mathrm{CH}$ soil. The results on the dry side of optimum showed considerable scatter. The range for the MI soil was about 4 pcf, for the CL soil about 5 pcf and for the $\mathrm{CH}$ soil about 9 pcf. These results also indicate that the amount of scatter produced in the compaction results is related to the inherent plasticity characteristics of the soil, viz., the higher the plasticity, the higher the variability. The strength test results were inconclusive. All samples were not mun at the desired moisture content, so comparison of the results obtained is misleading.

Studies of field compacted soils also show that the variations in density are related to the mean moisture level deviation from the optimum moisture content. In 
large scale field tests conducted by the Vaterways Experiment Station (1949), using various types of compaction equipment, little scatter was shown for wet side compaction, but large deviations were noted for compaction dry of optimum. For the particular set of test conditions used, increasing the roller weight did not appreciably increase the dry density obtained, but it did decrease the amount of scatter for dry side compaction.

The type of compaction equipment may also have a significant effect on the scatter produced in the test results. Pettitt (1967) shows results of several types of compaction equipment on the same soil. His results are shown in Table 2. Although the mean densities and moisture levels for each method are nearly the same, large variations exist in the standard deviations of the results. The sheepsfoot roller produced the least uniform results, but by combining the sheepsfoot and the pneumatic-tired construction traffic, a more uniform fill is produced.

Although it seems much work has been done on field dry density voriations, little has been done concerning the variations in shear strength.

A number of investigators have determined the coefficient of variation (ratio of the standard deviation to the mean) for the shear strength of natural soils within a particular soil zone. Extensive tests were 


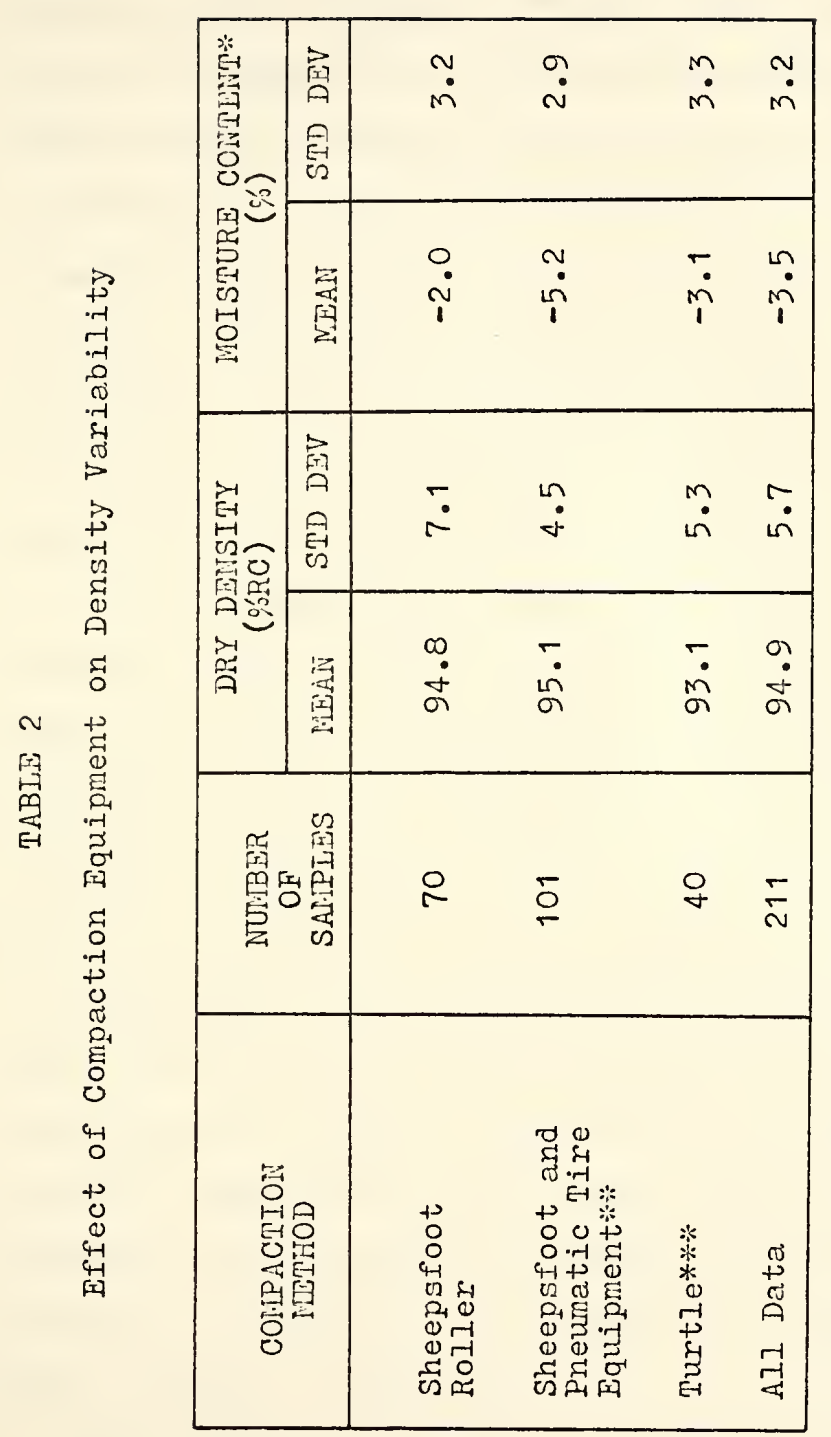

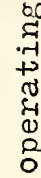

\&

(1) थ

30

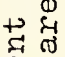

के

켱요

.

ร.ने

대용

दf 0

일

거다

0

究

क्ष

댕다

$\xi 0$

द्ञ

马

o o

- 4 工

to.

क्षा म

0

का

अิ

+ م.

용 丞

मिं

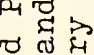

है तु

ते

엉 요

สิต

$+02$.

is $\rho_{1} p$

$\circ 0$ d

+ $द$

$+0$

(1) \& 0

口园

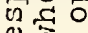

\& 0

द व

+ 0 도

उत ब

*炎水 
conducted by Hooper and Butler (1966) to determine the undrained shear strength of London clay. They have shown that for a number of sites, providing sound sampling techniques are followed, the coefficient of variation is limited to a range of approximately 0.17 to 0.22 . If sampling methods were poor, (e.g. sampler driven by impact rather than by hydraulic pressure), then the coefficient of variation jumped to values as high as 0.30 to 0.43. Ward, Samuels and Butler (1959) also indicate coefficients of variation ranging from 0.17 to 0.22 for tests on the Iondon clay. Iumb (1966) reports a coefficient of variation of 0.18 for a Hong Kong marine clay. An examination of the above cited data reveals that the coefficient of variation and shear strength of a variety of soils are roughly proportional; that is, an increase in shear strength will be accompanied by an increase in the coefficient of variation. This linear relationship is also supported by investigations cited by Morse (1972) for glacial soils located in Illinois. There was a fairly good linear relationship between the mean unconfined strength and the standard deviation of strength, even though the locations of the soils covered a large area.

This study will examine by statistical methods the density and strength variability in relation to the soil type, compaction method, molsture level and compaction energy. 


\section{Structure of Comnacted Clays}

Theories presented by Lambe (1958) and by Seed and Chan (1959) suggest that clays compacted at moisture contents less than optimum would have a flocculated structure, while samples compacted at moisture levels greater than optimum would tend to have a more dispersed microstructure, with a primary particle orientation normal to the axis of compaction. However, investigations by Sloane and Kell (1966), using the electron microscope, showed no evidence for edge to face structure for their laolinite samples compacted dry of optimum. Rather, they found an essentially random arrangement of particle domains. For compaction wet of optimum moisture, their results do indicate some orientation of the domains normal to the compaction axis. Results presented by Diamond (1971) also show this preferred particle orientation normal to the axis of compaction. However, Diamond's results indicate that the degree of orientation remains fairly constant (rather than increasing) as the moisture content increases above optinum moisture content.

Hodek (1972) used this "domain of particles" theory to treat the structure of compacted clays on a much more complex structural level than assumed by Iambe. Smart (1969) defined domains as a collection of platey particles, with the size of the collection being much larger than the size of the individual particles. Hodek notes that 
as water is added to the dry soil and afitation occurs from mixing, the domains tend to join together, swell, and form agrregates. As more water and mixing occur, these aggregates increase in size and decrease in number. This phenomenon results in the formation of macroscopic balls (aggregates) of various sizes, depending on the amount and distribution of water in the system. Compaction densification results from a rearrangenent of these macro-aggregates into a more efficient packing arrangement through displacement and if the moisture content is high enough, through plastic deformation. At low moisture contents, the aggregates are relatively rigid and not deformable, and their packing tends to leave a large amount of void space (inter-aggregate voids), while higher moisture aggregates can deform to fill these voids. Studies of pore size distribution data presented by Ahmed (1971) indicate that samples compacted at the same moisture content to the same dry density using various compaction methods will exhibit nearly identical pore size distributions. Ahmed used kneading (Harvard Miniature), impact (Proctor) and static compaction methods. His compacted samples were tested in unconfined compression, in an effort to correlate shear strength behavior with the observed pore distribution. For compaction dry of optimum, samples failed in a brittle manner, which Ahmed attributes "... apparently in part to the break down in 
large pores, which are present in large numbers" in this moisture region. Samples compacted wet of optimum behaved more plastically, without apparent fracture.

Diamond (1971) and Bhasin (1975) present pore size distribution for soils at various moisture content levels (wet of, dry of, and at optimum moisture content), compacted by the impact method at several effort levels. The pore size distributions fall into two distinct groups: those compacted at or above optinum moisture content for the level of effort used, and those compacted less than optimum. For samples compacted at or wet of the optimum moisture content, the distribution of voids are nearly identical. In each case, there are almost no voids larger than about $0.144 \mathrm{~m}$ in diameter. Samples compacted dry of optimum moisture content show a considerable amount of large size voids. All moisture levels show a considerable and approximately constant volume of the very small pores. Data presented for compaction near and dry of the optimum moisture content show that as the compaction energy increascs, the volume of large pores decreases; however, the distribution and quantity of smaller pores remains nearly constant. Diamond suggests that these smaller pores are largely gaps between individual kaolinite plates within the domains (intraagrregate voids). Scanning electron micrographs of these samples show that, for the samples compacted dry 
of optimum, neighboring domains touch at contact points but not generally along surfaces. In contrast, the domains are in sufficiently close contact that boundaries are difficult to distinguish for compaction wet of optimum.

Diamond's data shows that for compaction wet of optimum, a small amount of swelling occurs. Sridharan, Altschaeffl and Dianond (1971) also found this observation to be true. Their results show that increasing the compactive effort at high degrees of saturation will actually tend to increase the volume of the very small pores (the larger pores have been essentially eliminated at this moisture level).

The existence of a large amount of voids presents a possibility of different packing arrangements. It should then be expected that larger variations in density will be possible in these regions. Since a shear failure is produced between aggregates, not through them, then the large void region should also exhibit a large variation in shear strength. It is expected that the density and strength variability will be dependent on the moisture content and compaction energy, but relatively independent of compaction method. These ideas served as the basis of the statistical model developed to explain the density and strength variability in the compacted soils. 


\section{EXPERIIENTAL PROCEDURES}

\section{Introduction}

An effort was made to establish relationships among ary density, moulding water content, shear strength and their corresponding variabilities for laboratory compacted soils. Specimens were compacted in the laboratory by various compaction methods and then tested in unconfined compression in the as compacted state (no soaking was attempted). Statistical relationships were developed to explain the observed laboratory behavior. These relationships were then compared with field compaction results to determine how the laboratory relationships could be used to predict field performance.

\section{Iaboratory Testing Program}

The laboratory testing program was divided into two main phases, each phase involving a different soil type. The information concerning phase one of the testing program was covered by Peterson (1975). The emphasis here is directed primarily toward the soil used in phase two of the laboratory testing program.

About 1000 lbs. of this second soil type was taken from the borrow area for an embankment being constructed 
by the Indiana State Highway Commission (ISHC), under project number STF-95(12), located near Carbondale (Warren County), Indiana, during the summer construction season of 1975. The soil was air dried in the laboratory, pulverized by hand, sieved to remove the material greater than $\frac{1}{4}$. diameter and stored for further use. The results of identification tests performed on the soils are shown in Table 3. Figure 1 shows the grain size distribution curve for the soil tested.

\section{TABLE 3}

Identification Test Results

$\begin{array}{ll}\text { Liquid Iimit (\%) } & 20 \\ \text { Plastic Iimit (\%) } & 14 \\ \text { Plasticity Index (\%) } & 6 \\ \text { Specific Gravity of Solids } & 2.73 \\ \text { AASHO Classification } & \text { A-4(5) } \\ \text { Unified Classification } & \text { CI-MI } \\ \text { Descriptive Name } & \text { Gray Silt }\end{array}$

The soil was compacted in the laboratory using primarily the impact method, but some kneading compaction was also used. Four different levels of energy were used for the impact method of compaction, shown in Table 4. The energy ratio shown was used as a variable in subsequent statistical analyses. The kneading compaction was accomplished using the Harvard Miniature compaction apparatus as described by Wilson (1950). The number of 


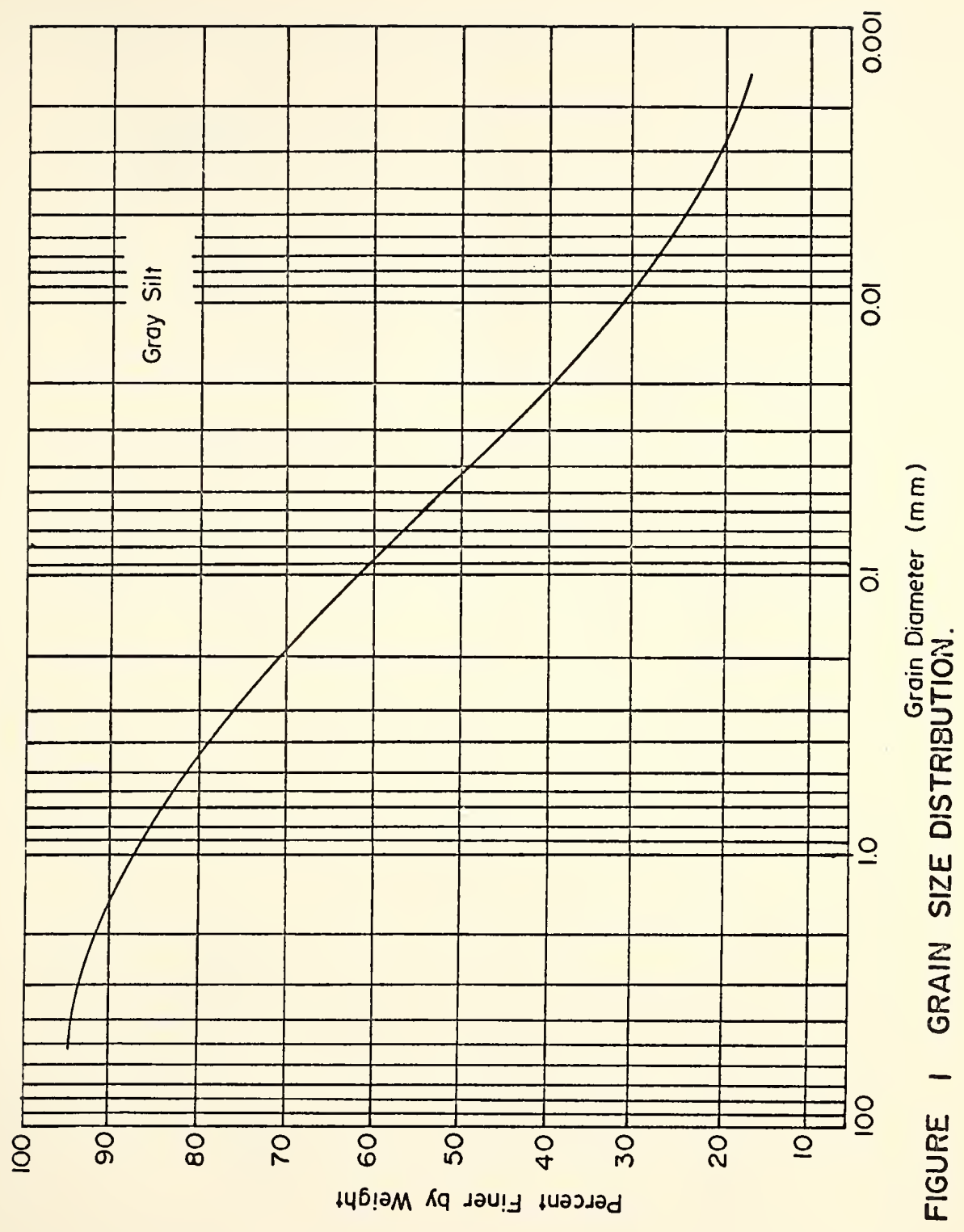




\begin{tabular}{|c|c|c|c|c|c|c|}
\hline \multirow{4}{*}{ 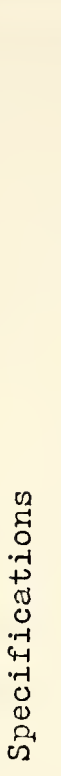 } & 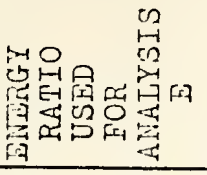 & $\begin{array}{l}8 \\
0\end{array}$ & $\stackrel{6}{\circ}$ & $\begin{array}{l}\text { ำ } \\
\dot{+}\end{array}$ & $\overrightarrow{0}$ & 1 \\
\hline & 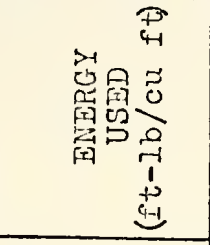 & $\begin{array}{l}\dot{8} \\
\dot{8} \\
\sim\end{array}$ & $\begin{array}{l}\dot{8} \\
\dot{4} \\
\stackrel{-}{-}\end{array}$ & $\begin{array}{c}0 \\
\stackrel{0}{n} \\
m \\
m\end{array}$ & $\begin{array}{l}\dot{8} \\
0 \\
0 \\
i n\end{array}$ & 1 \\
\hline & 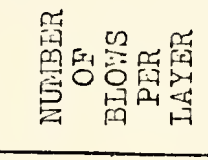 & $\stackrel{L}{\sigma}$ & $\stackrel{\operatorname{Ln}}{\sim}$ & $\stackrel{\text { n }}{\sim}$ & $\stackrel{1 n}{N}$ & $\stackrel{9}{4}$ \\
\hline & 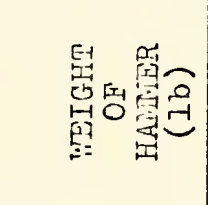 & in & in & $\begin{array}{l}0 \\
\dot{0}\end{array}$ & $\stackrel{0}{\stackrel{0}{0}}$ & 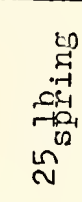 \\
\hline $\begin{array}{l}0 \\
0-1 \\
+3 \\
0 \\
0 \\
0 \\
0 \\
0 \\
0 \\
0\end{array}$ & 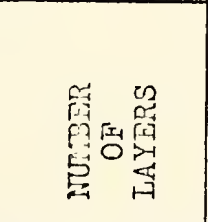 & $m$ & $m$ & $m$ & in & in \\
\hline 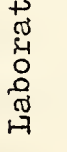 & 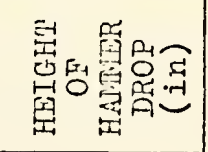 & $\stackrel{\sim}{\leftarrow}$ & $\stackrel{N}{\sim}$ & $\stackrel{\omega}{\leftarrow}$ & $\stackrel{\infty}{\leftarrow}$ & 1 \\
\hline & & 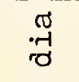 & ס ס ס & 品 & 芴 & $\mathbb{\infty}$ \\
\hline & A & $\begin{array}{l}0 \\
j\end{array}$ & i & $\dot{0}$ & ن & $\begin{array}{r}\text { न्ठ } \\
\times 10\end{array}$ \\
\hline & 结约记 & 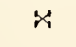 & $x$ & $x$ & $x$ & $6=$ \\
\hline & & $\begin{array}{l}\varphi \\
\dot{j}\end{array}$ & $\begin{array}{l}\varphi \\
\dot{\sigma}\end{array}$ & $\stackrel{0}{\dot{\sigma}}$ & $\stackrel{10}{\dot{j}}$ & $\dot{v}^{\infty}$ \\
\hline$=$ & 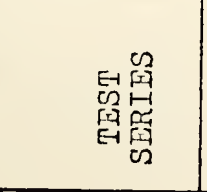 & 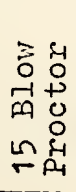 & 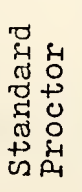 & 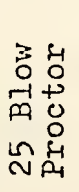 & 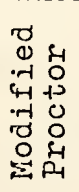 & 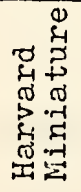 \\
\hline
\end{tabular}


layers, spring weight and tamps per layer were varied in order to produce a maximum dry density which was approximately the same as the maximum dry density obtained by the Standard Proctor compaction method. See Table 4. It was not possible to obtain the same maximum density at the same optimum moisture content because of the differences in compaction method.

Twenty-four hours prior to the time of compaction, the required amount of soil necessary for one test was removed from storage, and the amount of distilled water necessary for the desired moisture level was gradually added by means of a hand atomizer. All mixing of the soil during water addition was done by hand. The soil was then sealed in a plastic bag and stored in a 55 gallon covered barrel (maintained at nearly 100\% relative humidity) for 24 hours prior to compaction.

After the soil was compacted in the Proctor mold, samples were obtained by simultaneously pressing three sharpened thin walled stainless steel samplers (3.5 in. long $x 1.485$ in. outside diameter with a 0.025 in. wall) into the soil with a hydraulic jack as shown in Figure 2. The sampling tubes and compaction mold were both lubricated with silicone oil before samplins. The samples were then extruded from the sampling tubes, ends trimmed, diameter and height measured, weighted, sealed in plastic bags, and stored in a humidifier, in a constant 


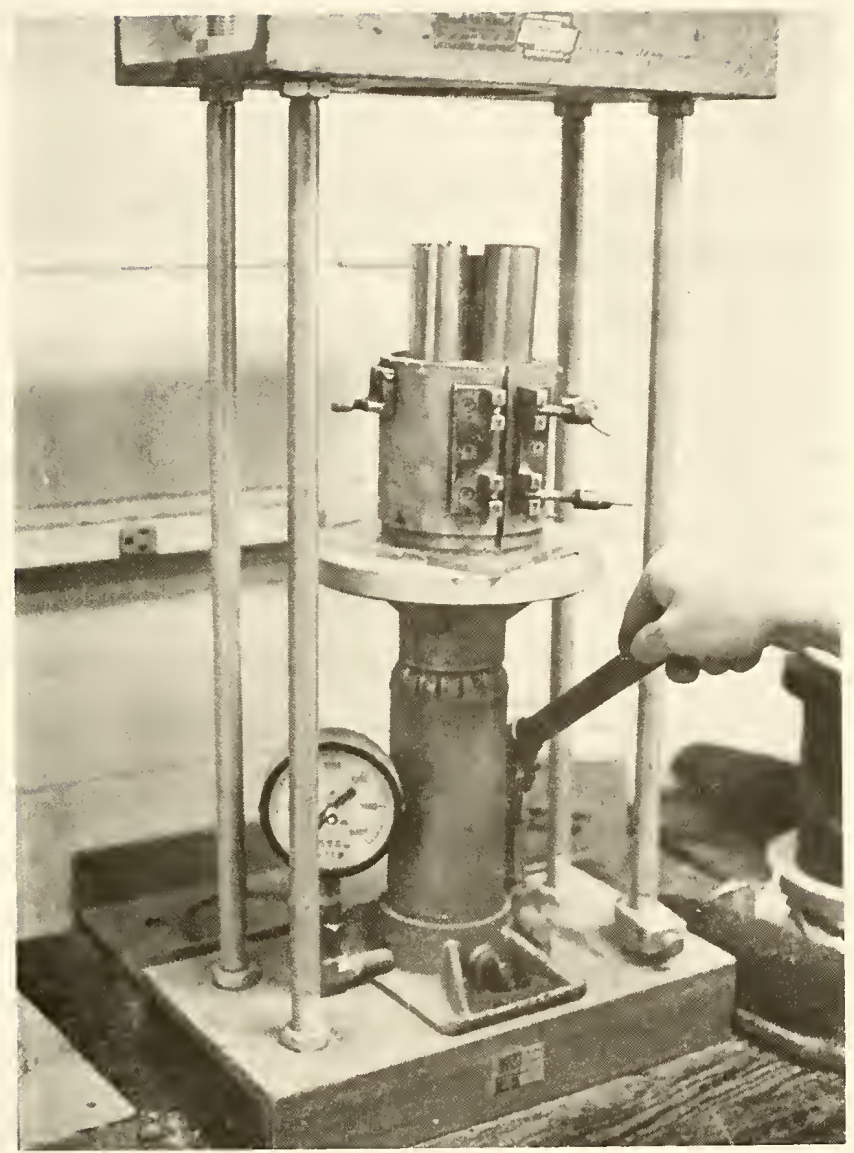

FIGURE 2 METHOD OF OBTAINING STRENGTH SAMPLES FROM PROCTOR MOLD. 
temperature room, until time for strength testing. The atmosphere inside the humidifier was maintained at nearly 100\% relative humidity. For the highest impact energy used (Modified Proctor), it was not possible to obtain strength samples for moisture contents less than about 10\%. When sampling tubes were pressed into the soil compacted much drier than $10 \%$ moisture, they tended to bend and become highly deformed, resultins in disturbed, unusable strength samples. When compaction was accomplished with the Harvard Miniature apparatus, the entire sample was used for strength testing after extrusion from the compaction mold.

A five day curing time was allowed between the time of compaction and the time of strength testing because there was evidence of a change in strength during the first few days after compaction. To evaluate the changes expected for this soil, a series of nearly identical Harvard Niniature samples were tested in a timed series. The change in strength and moisture content as a function of time is show in Figure 3. Similar results were reported by Highter (1969) for a sandy clay. Highter's results show a strength decrease of approximately $12 \mathrm{psi}$ over a period of 5 days.

As noted by Hishter, et al. (1970), the temperature during compaction and testing can greatly influence test results; thus the influence of temperature was kept to 
둥

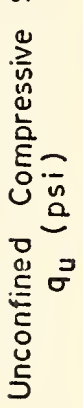

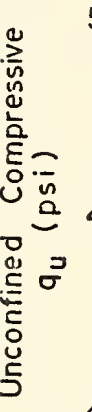

Horvard Miniofure

Somples-Groy Silt

5 Layers - 40 Tamps / Layer 25k Spring $\bar{\gamma}_{d}=121.7$ pcf

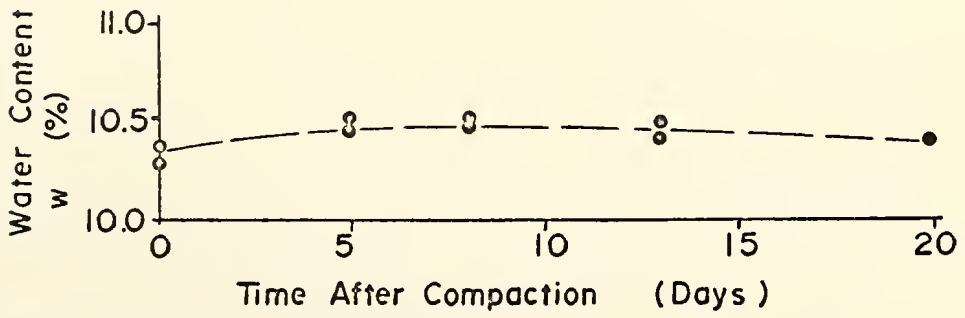

FIGURE 3 STRENGTH AND WATER CONTENT CHANGES AS A FUNCTION OF STORAGE TIME. 
a minimum by compacting in the laboratory under moderately fluxuating ambient temperatures of about $22^{\circ} \mathrm{C}\left( \pm^{\circ} \mathrm{C}\right)$, and then storing and testins samples in a controlled temperature of about $22^{\circ} \mathrm{C}\left( \pm^{\circ} \mathrm{C}\right)$.

\section{Field Testing Prosram}

An Indiana State Highway Comrission (ISHC) relocation project (Project STF-95(12) near Carbondale (Warren County), Indiana) was used to obtain samples of field compacted soils during the construction seasons of 1974 and 1975. For the most part, compaction was accomplished through the use of a single piece of compaction equipment (a self-propelled tamping foot Hyster Roller, Model C45OB, approximately 27 tons in weight). Since the project was a normal construction operation, it was not possible to control the compaction variables. No control was possible over the compaction, as the sampling was an add-on to the existing construction project, nccessitating no interference with usual construction procedures. In particular, it was difficult to establish the amount of energy (number of passes) uscd in the compaction process for a Given sampling location on the grade. Also, non-uniformity of the application of energy was a problem.

During the first sampling season (summer 1974), many problems were encountered which limited the amount of usable data obtained. These problems were outlined 
elsewhere (Peterson, 1975) and will not be dealt with here. During the second season, however, the sampling program produced a large amount of useable data. The samples were taken from an embankment being constructed as part of the highway interchange. The soil used for construction was taken from a single borrow area, and was fairly uniform. In order to obtain many samples from various locations within a single compacted lift, sampling was normally carried out at the finish of the day's construction activities. In this manner, sampling could be carried out without interfering with the normal construction routine.

The amount of effort used in compacting the soil was recognized as an important variable. Since exact quantification of this variable was not possible, three hypothetical "energy areas" were located within the embanloment being compacted. The central portion of a lift under compaction was termed a "high energy area" because of the tracking in this area by the construction equipment, trucks and cars. A strip of about ten feet wide on each edge of the embankment was termed a "medium energy area". This area received little additional traffic other than the compaction equipment. It should be noted that samples from the high and medium energy areas were taken only after the lift had met the construction specification and had been passed by the ISHC 
inspector. Any lift which had not passed the construction specification at the finish of the working day was termed a "low energy area". During the 1975 construction season, a total of about 60 undisturbed drive tube samples were taken from these three hypothetical energy areas. Difficulties encountered in trimming and extruding the samples prevented the testing of all 60, but a total number of 40 samples were eventually strength tested. The drive tube apparatus is shown in Figure 4. The samples were extruded in the field, sealed in plastic bags, and stored in the laboratory humid room until ready for strength testing. The field samples were tested 5 days after they were compacted, the same as the laboratory samples.

\section{Unconfined Testing Apparatus}

Because a large number of strength test samples were anticipated, an unconfined compression apparatus was developed which utilized an on-line analog computer and $X-Y$ plotter to reduce and record the strength testing data. The apparatus developed is shown in Figure 5. The axial load was supplied by a Model 56 Wykeham Farrance loading frame with a 1 ton capacity. The displacement rate selected was 0.05 inches per minute. The load and displacements were continuously measured by a load cell and linear variable differential transformer (IVDT) 


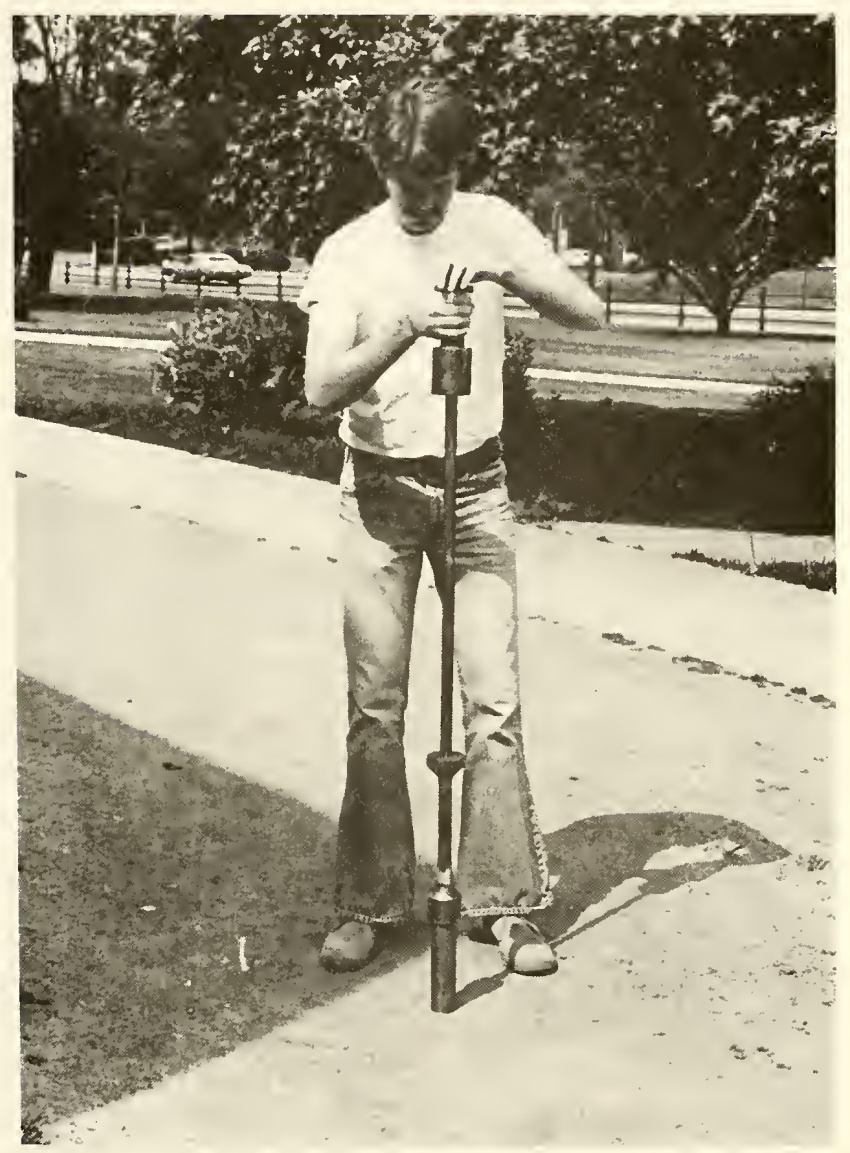

FIGURE 4 FIELD DRIVE TUBE SAMPLING APPARATUS. 


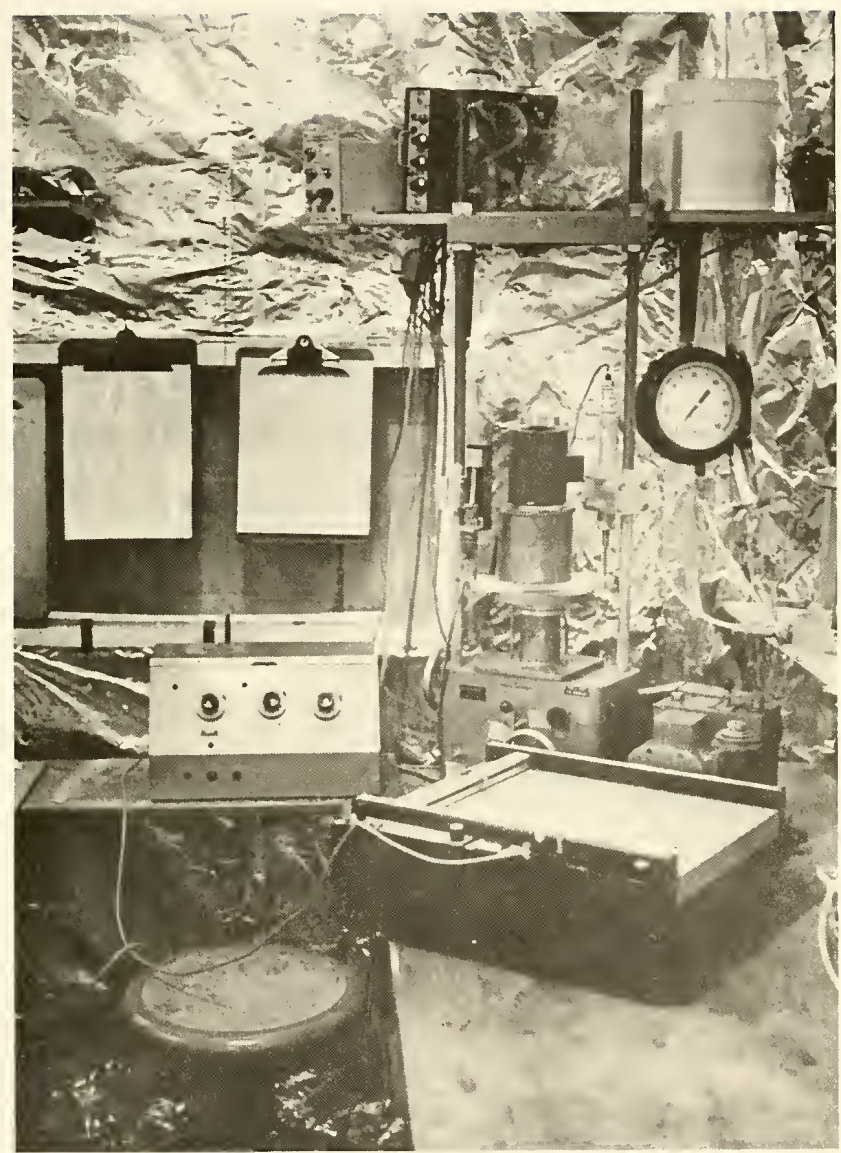

FIGURE 5 UNCONFINED TESTING APPARATUS. 
respectively. By entering the sample dimensions (length and diameter) into the analog computer, the load/deformation data were automatically converted to stress/strain data. These data were continuously recorded on the $X-Y$ plotter, in the form of the standard stress-strain plot. No further data manipulation was necessary. Some typical stress-strain curves are shown in Figure 6 . The strength of the sample was defined as the peak of the stress-strain curve, when one existed, or the stress at $20 \%$ strain. 


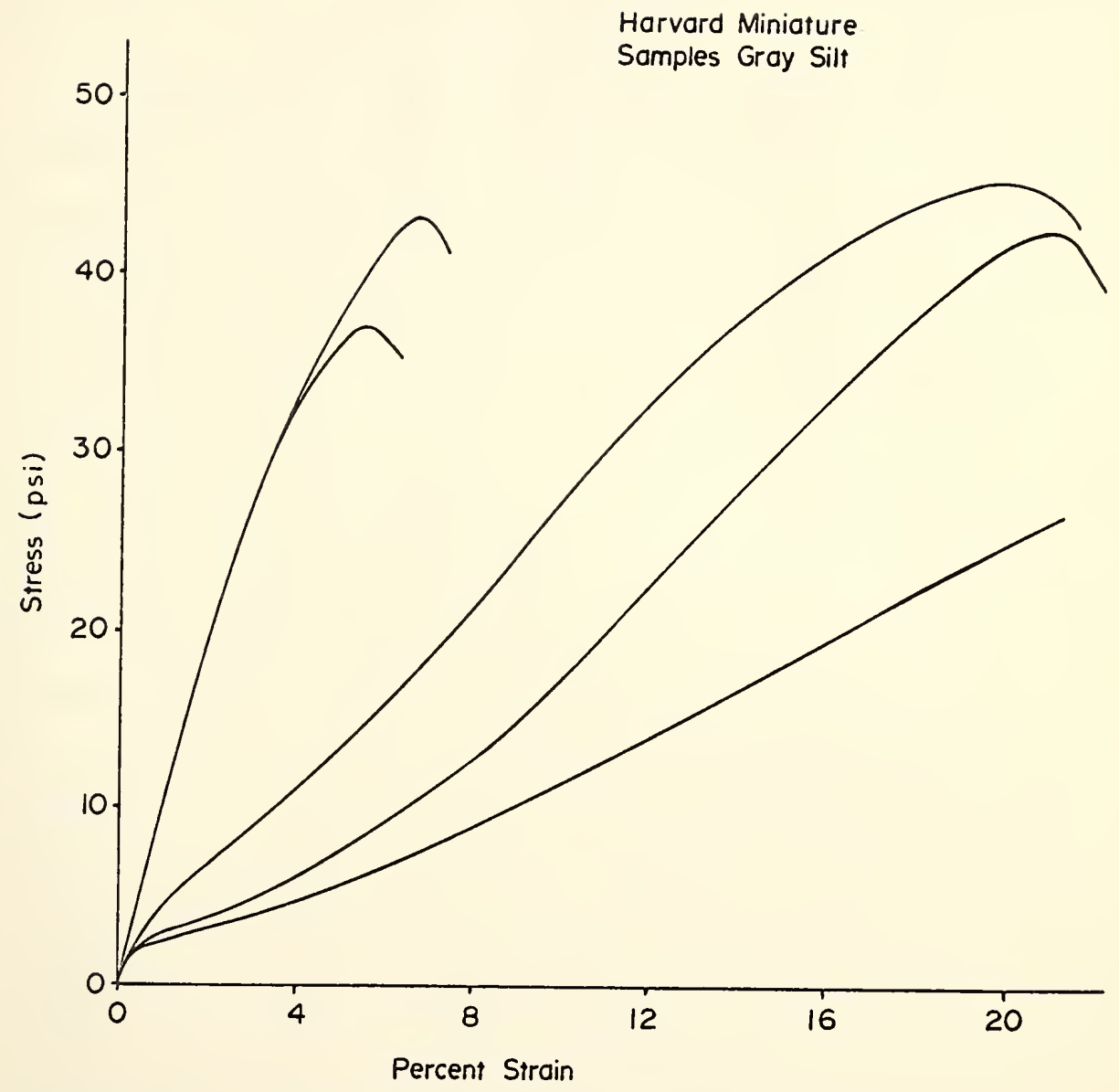

FIGURE 6 TYPICAL STRESS-STRAIN CURVES. 


\section{ANALYSIS OF EXPERIMENTAL RESULTS}

\section{Statistical Analysis}

A total of 226 samples were tested in unconfined compression in connection with the second phase of the laboratory testing program. This total was comprised of 105 laboratory impact compacted samples, 81 Harvard Miniature compacted samples, and 40 rield Hyster compacted samples. The entire set of data obtained is presented in the Appendix.

The new data were handled in different manners, depending on whether the actual magnitude of the dependent variable or the magnitude of its variation was under consideration. If the actual magnitude was under consideration, all the data obtained were used for the analysis. If the magnitude of the variability was being considered, it was nccessary to break the data into subsets, to calculate the means and variances within each subset, and then to perform the desired analysis using this reduced data set. These reduced data sets were broken up into $1 \%$ moisture content intervals with respect to the optimum moisture content for the particular effort level under consideration. 
A least squares regression analysis approach was used to isolate the effects of the independent variables on the chosen dependent variable. If the simple example regression model

$$
Y_{\text {est }}=a+b X
$$

where $Y_{\text {est }}$ is the dependent variable, $X$ is the independent variable, and $a$ and $b$ are the estimated regression constants

is considered, then the least squares method minimizes the squared deviations about this regression model. Referring to Figure 7, the total variation of $Y$ is defined as the $\sum(Y-\bar{Y})^{2}$ or the sum of the squares of the deviations of the values of $Y$ from their mean $\bar{Y}$. The unexplained variation is $\sum\left(Y-Y_{\text {est }}\right)^{2}$ where $Y_{\text {est }}$ is the regression estimate, since the deviations ( $Y-Y_{\text {est }}$ ) behave in a random or unpredictable manner. The explained variation is $\sum\left(Y_{\text {est }}-\bar{Y}\right)^{2}$ which has a definite pattern. The analysis tries to fit the model such that the unexplained variations are kept to a minimum. A useful statistical parameter for determining the amount of unexplained variation is the coefficient of correlation, $R$, which is defined as

$$
R= \pm \sqrt{\frac{\text { Explained Variation }}{\text { Total Variation }}}= \pm \sqrt{\frac{\sum\left(Y_{\text {est }}-\bar{Y}\right)^{2}}{\sum(Y-\bar{Y})^{2}}}
$$




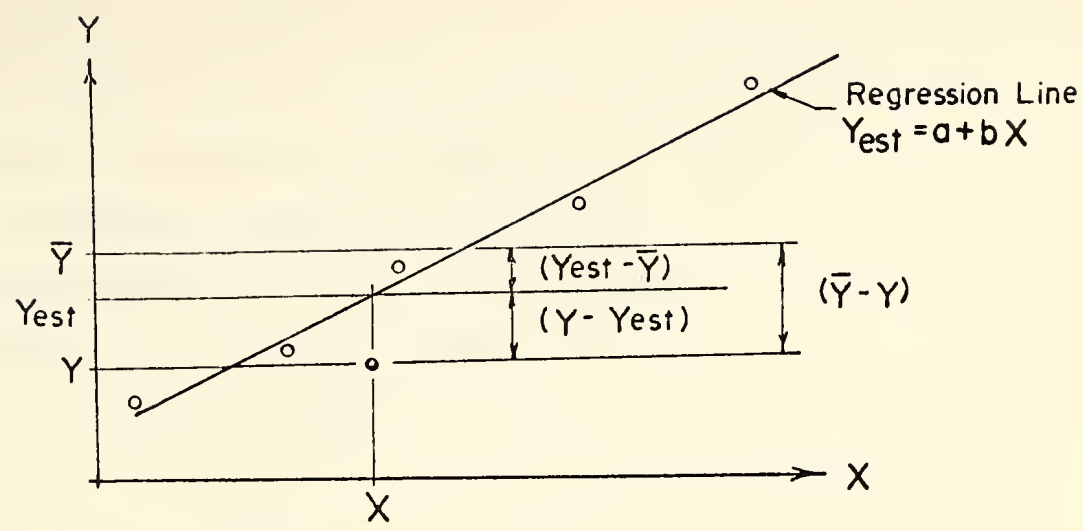

FIGURE 7 REGRESSION TERMINOLOGY.

A coefficient of correlation of unity indicates no unexplained variations, while an $\mathrm{R}$ of zero indicates that all the variation is unexplained.

Often a "goodness of fit" statistic is interpreted as $\mathrm{R}^{2}$, and when multiplied by $100 \%$ roughly indicates the percentage of the variation explained by the regression equation.

The a.ll-possible regression approach was used as an initial evaluation of the importance of the independent variables. The Purcue computer program DRRSQU was used for this phase of the analyses. Different models (combinations of independent variables) were used for 
the different dependent variables. The analysis systematically fitted the data to different models, and reported the resulting $\mathrm{R}^{2}$ values.

For example, suppose a relationship was desired between variable $A$ (the dependent variable) and variables $X, Y$, and $Z$ (the independent variables). Using the DRRSQU all-possible regression approach, regression relationships would be calculated expressing variabie $A$ as a function of variable $X$, then variable $Y$ and then variable $z$ (three models). The program would then report the $R^{2}$ coefficient for each model. These are the one term models. In the second step, variable $A$ is expressed as a function of the independent variables taken two at a time (i.e., variables XY, XZ and YZ). This results in three more models, with the three corresponaing $R^{2}$ values being reported. The final step in the analysis would be an expression relating variable $A$ and variable $X, Y$ and $Z$ (in one model). Again, the resultinó $\mathrm{R}^{2}$ value would be reported.

This method of analysis was used to indicate the relative importance of the independent variables, and provided a model for further detailed regrossion analyses. Once the important variables were isolated in the model, regression coefficients were easily obtained (using the SPSS regression option). This step results in the familiar "regression equation" or regression relationship. 
After obtaining the desired regression relationship, other items were checked to determine if the relationsinip was statistically meaningful. The 95\% confidence interval was checked for each regression coefficient. For the regression relationship to be consiajered meaningful, this confidence interval should not cross zero. Also, this confidence interval should be small.

Therefore, recression relationships were considered significant if they had a high $\mathrm{R}^{2}$, small confidence intervals for the regression coefficients and confidence intervals which do not cross zero.

It is recognized that one of the underlying assumptions of the least squares regression analysis is homogeneity of variances. The data sets were checked for homogeneity of variances using the Foster-Burr test, and were found homogeneous. It is unclear what statistical effect non-homogeneous data has on the least squares regression technique. If non-homogeneous data were encountered, certain transfornations are possible, but these transformations cause one to loose contact vith the significance of the variables. After meaningful relationships were developed for the laboratory compaction test results, the process was repeated for the field compaction results. It was hoped that statistical comparisons could be made between the two compaction methods. These comparisons would serve 
two purposes. First, they would determine if the variables had the same order of importance in the field and laboratory. Secondly, they would indicate the feasibility of making good field compaction predictions from laboratory data.

As previously mentioned, there was poor control over some of the field compaction vaxiables. Since the soil came from a single borrow area, it was relatively uniform, but, since it was from one source, the moisture contents fell in a narsor band. The compaction energy was variable, and largely unknown in level. The lack of control over these compaction variables severely limited the statistical analyses which could be performed on this field data.

Similarly, problems were encounterca when attempting to use any publishea data. Important bits of information were often missing from the published worlss. This also prevented the statistical analyses of many of these data.

Because of these aifficulties, it was felt that statistical inferences could be misleading. The field compaction data were not subjected to the same statistical analyses as the laboratory data; therefore, it was not possible to determine the relative effects produced by the field variables. The data sets were compared on a visual basis only, i.e., in terms of relative trends and magnitudes. 


\section{Statistical Results}

The first step in the statistical analysis of the laboratory results was to determine the independent variables significant in describing the magnitude of the dry density and shear strength. This analysis was done for three moisture content ranges:

1) considering all moisture contents together;

2) considering only data less than optimum moisture content;

3) considering only data greater than optimum moisture content.

The analysis was also performed on the magnitude of the laboratory compaction variability associated with the dry density and shear strength in order to determine which independent variables are significant in producing the observed variations. The independent variables and models chosen for both analysis are show in Table 5 . The independent variables shown in Table 5 are the linear terms used in the analysis. The second and third powers of all of these variables were also used. For example, the first independent variable shown, w (moisture content), was used for the analysis, as well as was $w^{2}$ and $w^{3}$. The results of the analyses are shown in Tables $6,7,8$ and 9 .

As an initial starting point for the analyses, the models indicated by the all-possible regression were 
TABLE 5

Statistical Models Used for Analysis

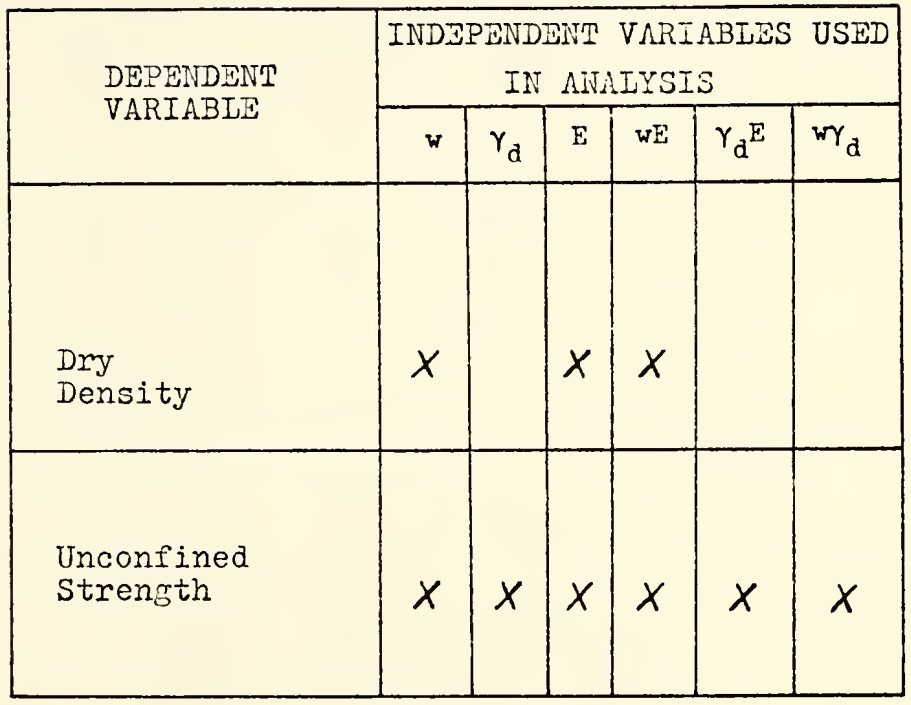




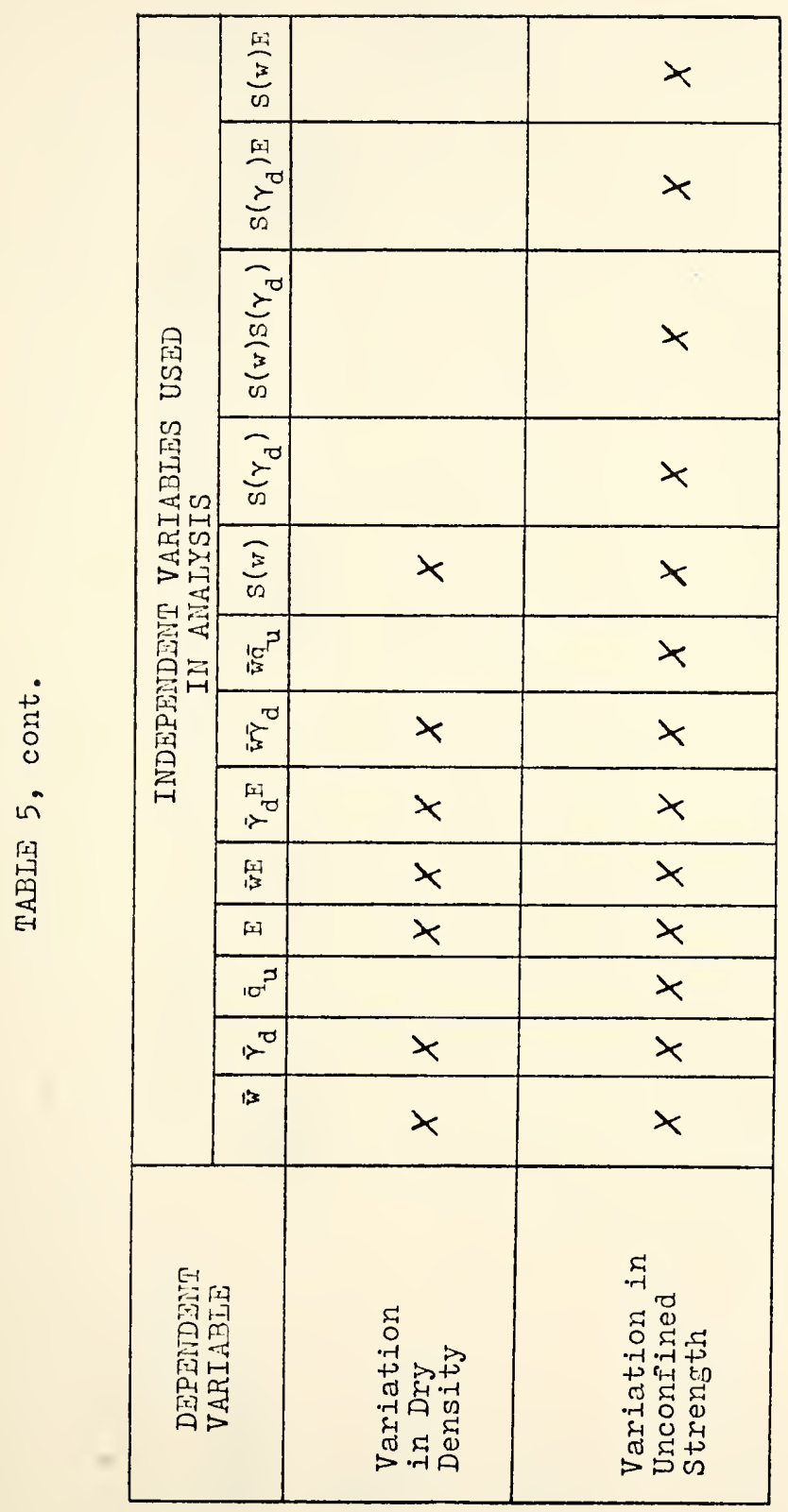




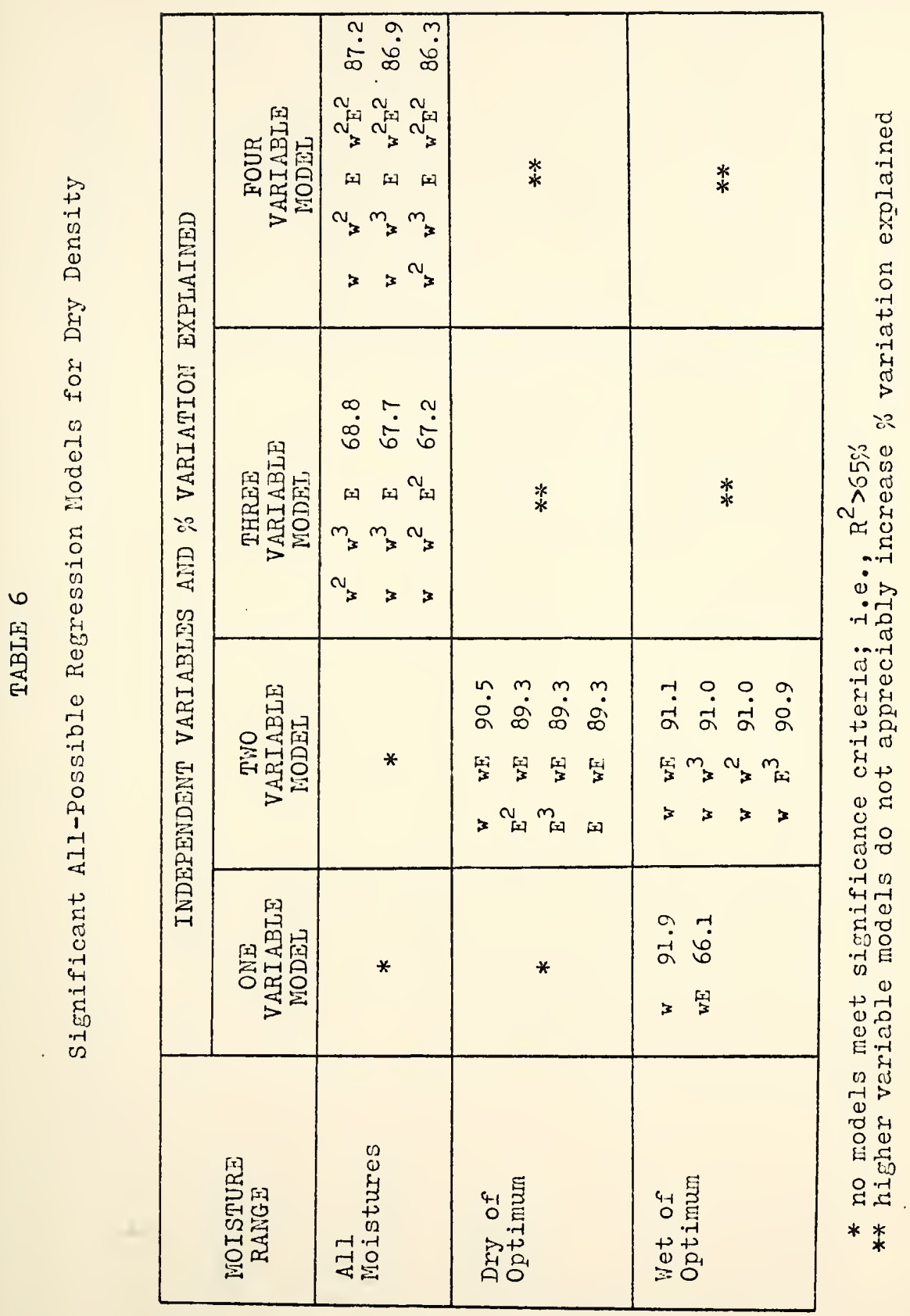




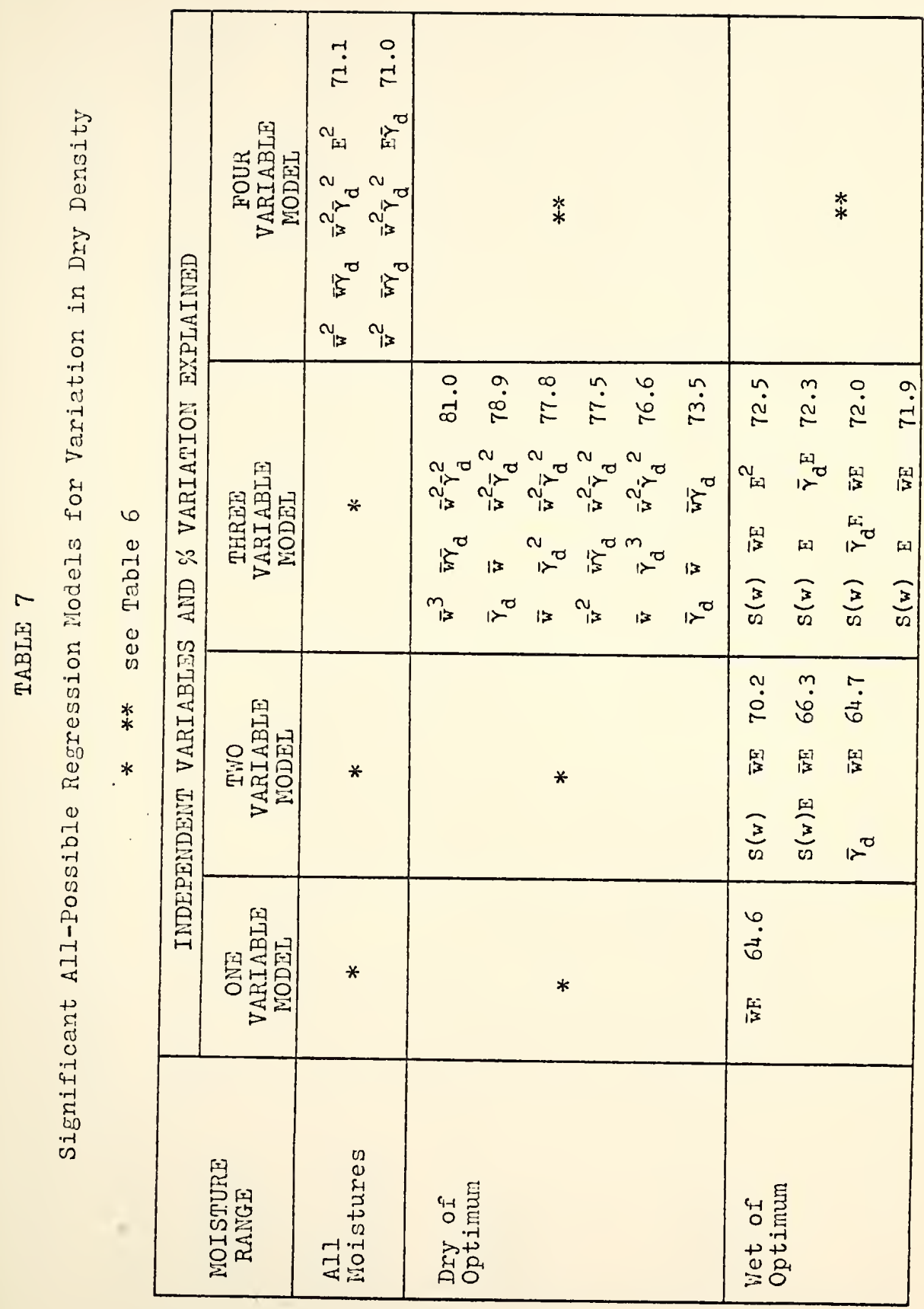




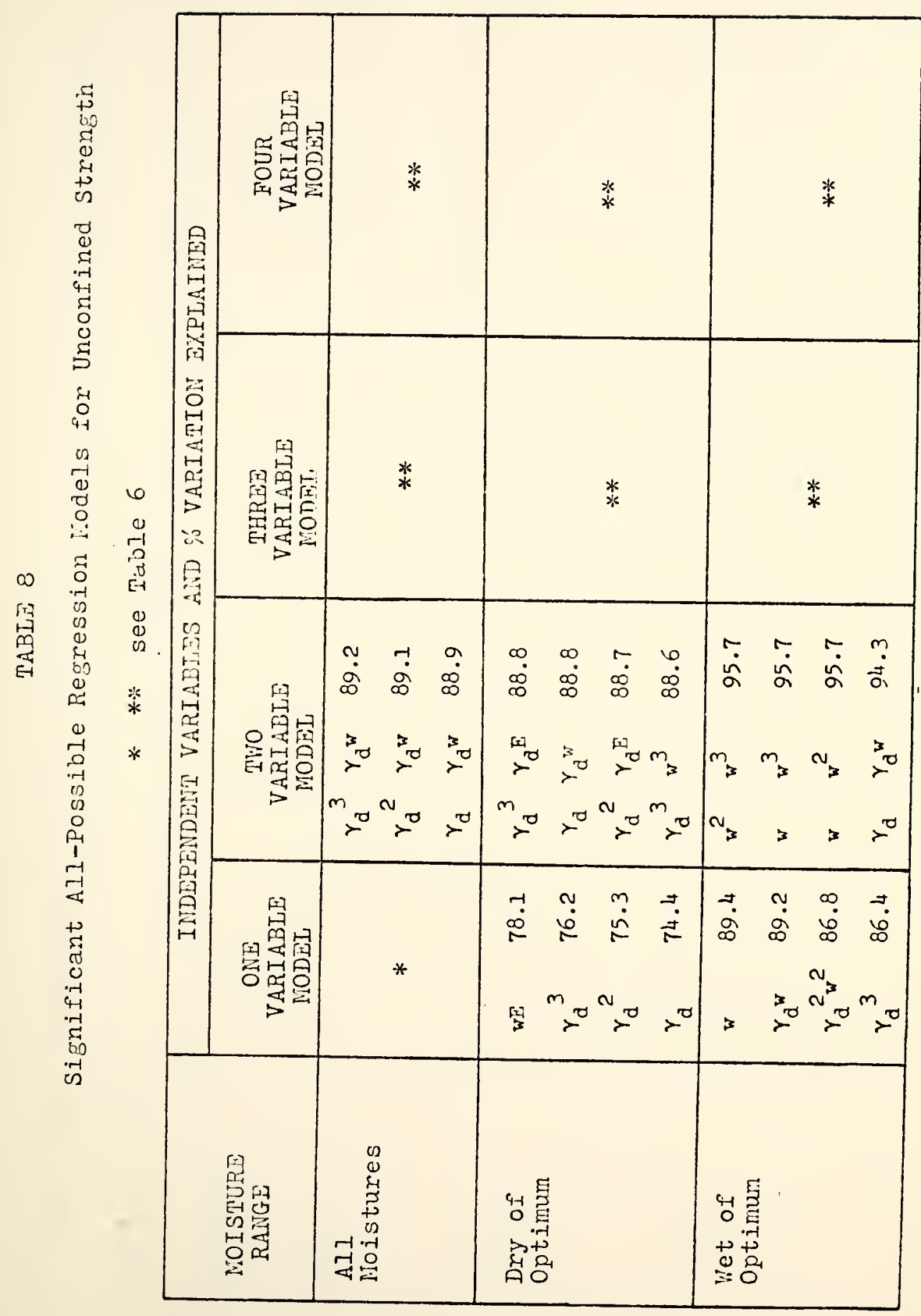




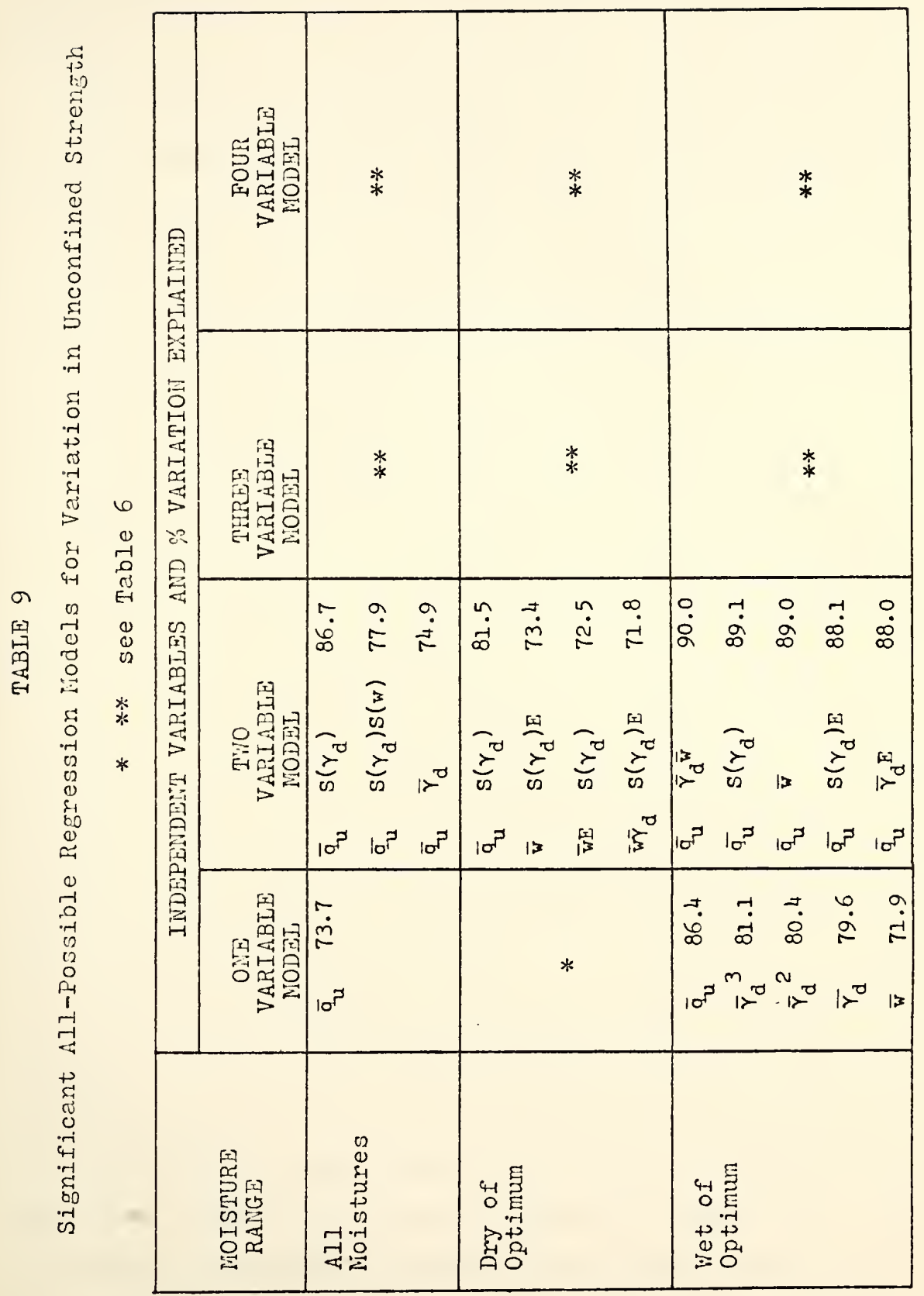


considered significant if the $R^{2}$ value was greater than 0.65 .

The density all-possible regression results, Table 6, indicate that it requires a relationship of three variables to satisfactorily describe the magnitude of dry density over all moisture contents, while a relationship of four variables is required to describe the variations in dry density over the same moisture range. However, by analyzing the data separately on the wet and dry sides of the optimum moisture content for that particular effort, better relationships, with fewer variables, were obtained. For this reason, the density and variation in density data were evaluated with respect to optimum. This problem was not present for the data on strength and variation in strength. Significant relationships with one or two terms were available for the entire moisture range, as well as the regions dry and wet of optimum. Therefore, regression relationships for all three moisture regions were developed for the strength and variation in strength models.

From the all-possible regression results, various models were chosen for further analysis. In the cases where there was little change in $R^{2}$ over several models, the one with the lowest order independent variables was selected. Using the non-linear regression technique, regression coefficients were fit to the models selected. 
The resultine density, variation in density, strength and variation in strength relationships are shown in Table 10.

The density and variation in density results show that the variation in water content, $S(w)$, may be an important variable in explaining the density results. However, since the magnitude of this variable was determined by the method of analysis used (i.c., dividing the data into one percent moisture increments), it was felt that this variable shoula not be included in further analysis. 


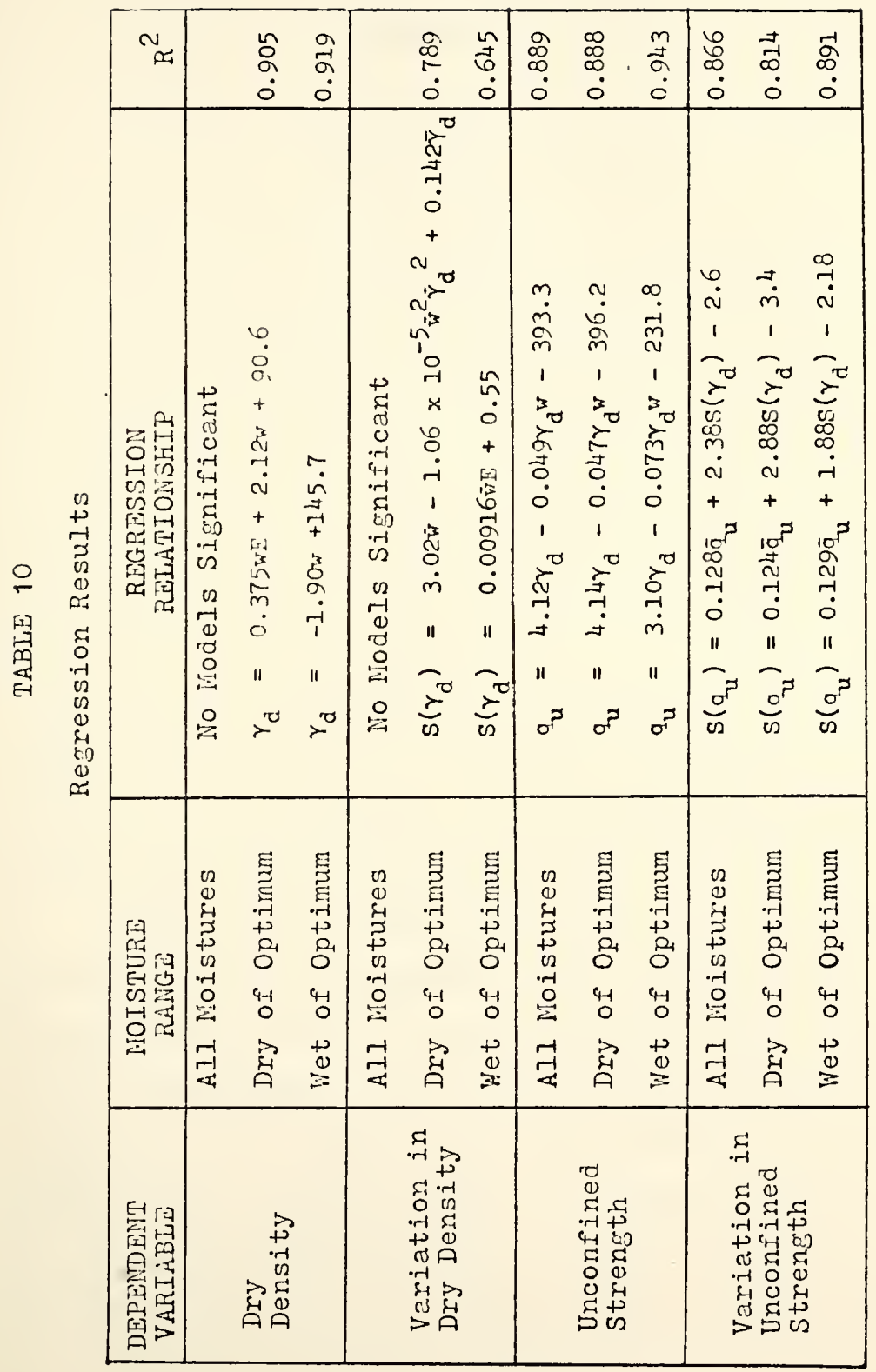




\section{DISCUSSION OF RESULTS}

\section{Magnitude of Dry Density}

The statistical relationship for the magnitude of dry density is best formulated when the effort curve is considered independently wet and ary of the optimum moisture content (OMC). It was shown earlier (Table 6) that for compaction ary of optimum, the magnitude of dry density is controlled by the water content and the interaction between water content and compaction energy. For compaction wet of optimum, the vater content alone is sufficient to quantify this variable. The resultant regression equations and laboratory data are show in Figure 8. The data shown are the mean values for the statistical subsets described earlier.

The statistical results are consistent with the observed compaction phenomena. For compaction at moisture contents dry of optimum, the addition of energy causes an increase in ary density at a constant moisture content. It is interesting to note that the resulting effort lines are not parallel for compaction dry of the optimum moisture content, but will increase in slope (toward the vertical) with increasing compaction enersy 


\section{O 15 Blow Procior \\ $\square$ Siandard Proctor \\ $\triangle 25$ Blow Proctor \\ $\nabla$ Modified Proctor \\ All for Gray Silt}

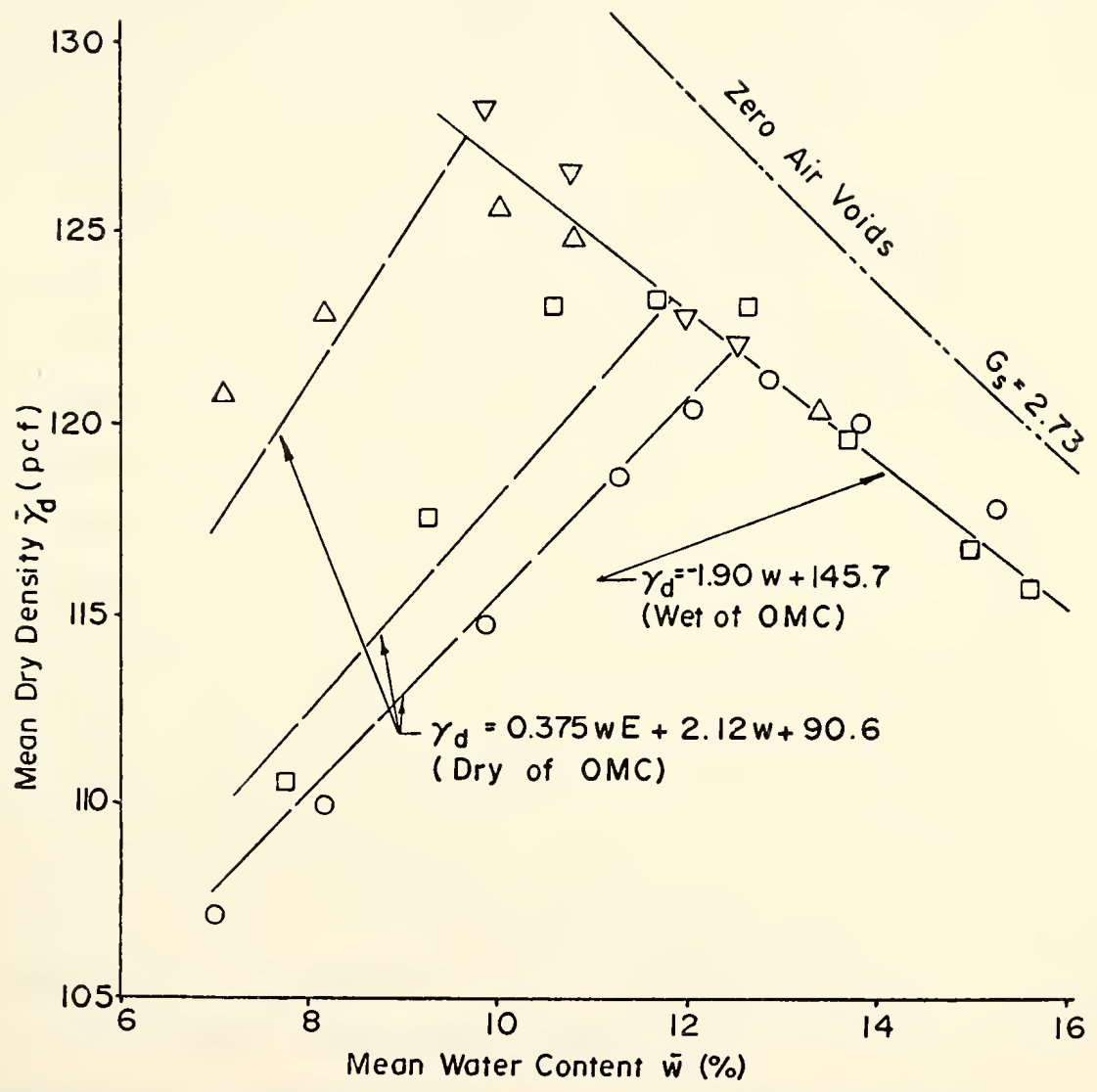

FIGURE 8 MOISTURE-DENSITY RELATIONSHIPS FOR LABORATORY COMPACTION. 
because of the moisture content and energy interaction term. However, for moisture levels greater than the optimum moisture content, the resultant dry density at any moisture content is relatively independent of compaction energy. The resulting dry densities fall roughly parallel to the zero-air-voids line in this region, and represents the limit of compaction efficiency.

A comparison of the Standard Proctor and Harvard Miniature compaction results in Figure 9 shows that the two compaction methods produce similar results for this soil, the Harrard Miniature densities being slightly greater than the Standard Proctor densities.

Figure 10 shows a comparison of the field compaction results for the gray silt, as well as the laboratory compaction prediction equation for the same soil, wet of optimum. The field data points shown are mean values for the statistical subsets. The results show that the field compacted soils follow a relationship similar to that established in the laboratory for soils compacted wet of optimum moisture content.

It is interesting to note that the means of all the measured field densities are greater than the ISHC compaction specification ( $95 \%$ of Standard Proctor maximum dry density) for this project. Therefore, the contractor on this project, using the particular piece 

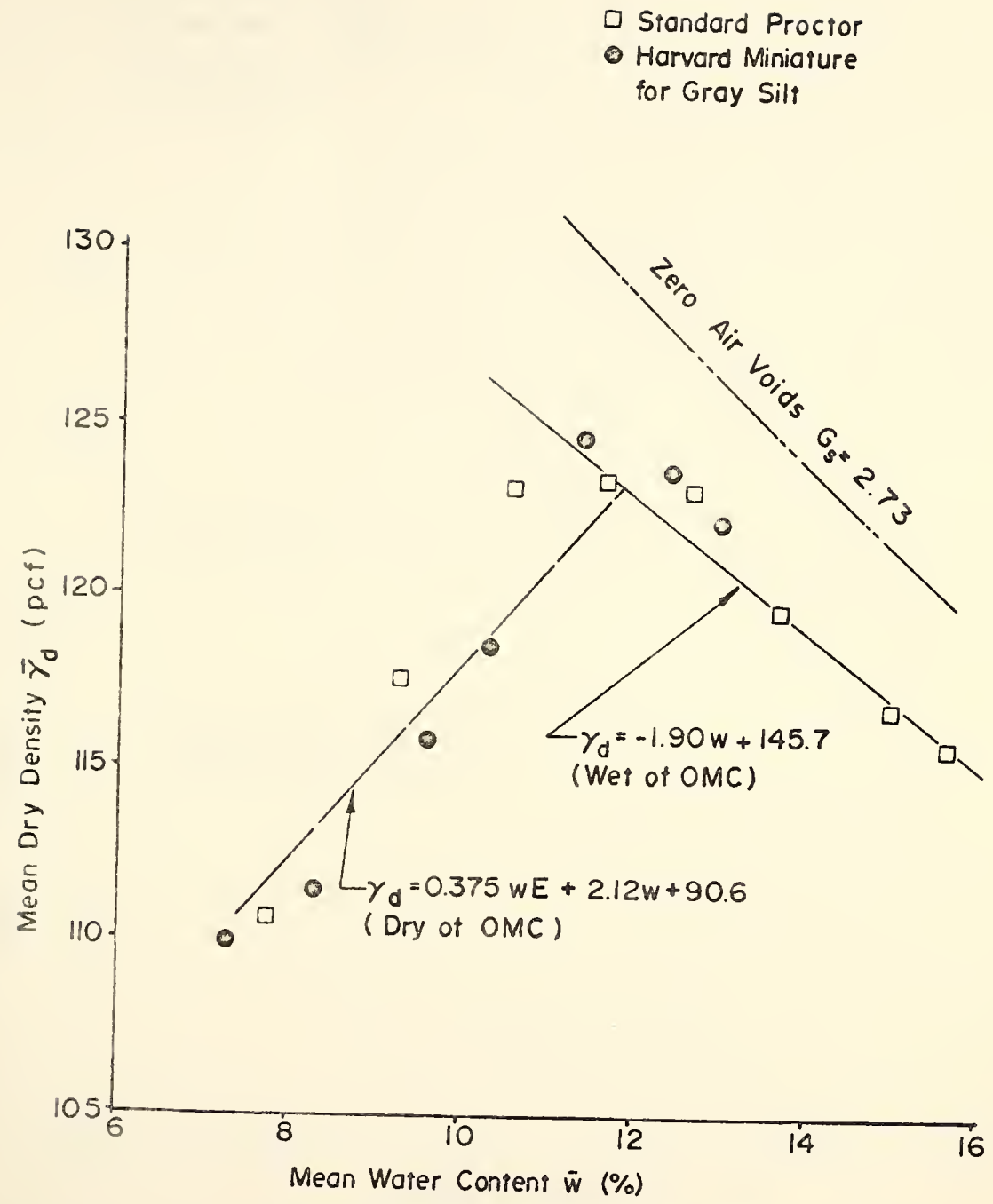

FIGURE 9 COMFARISON OF STANDARD PROCTOR AND HARVARD MINIATURE MOISTURE - DENSITY RELATIONSHIPS. 
O Low Energy Areo

$\square$ Intermediote Energy Areo

$\triangle$ High Energy Areo

for Groy Silt

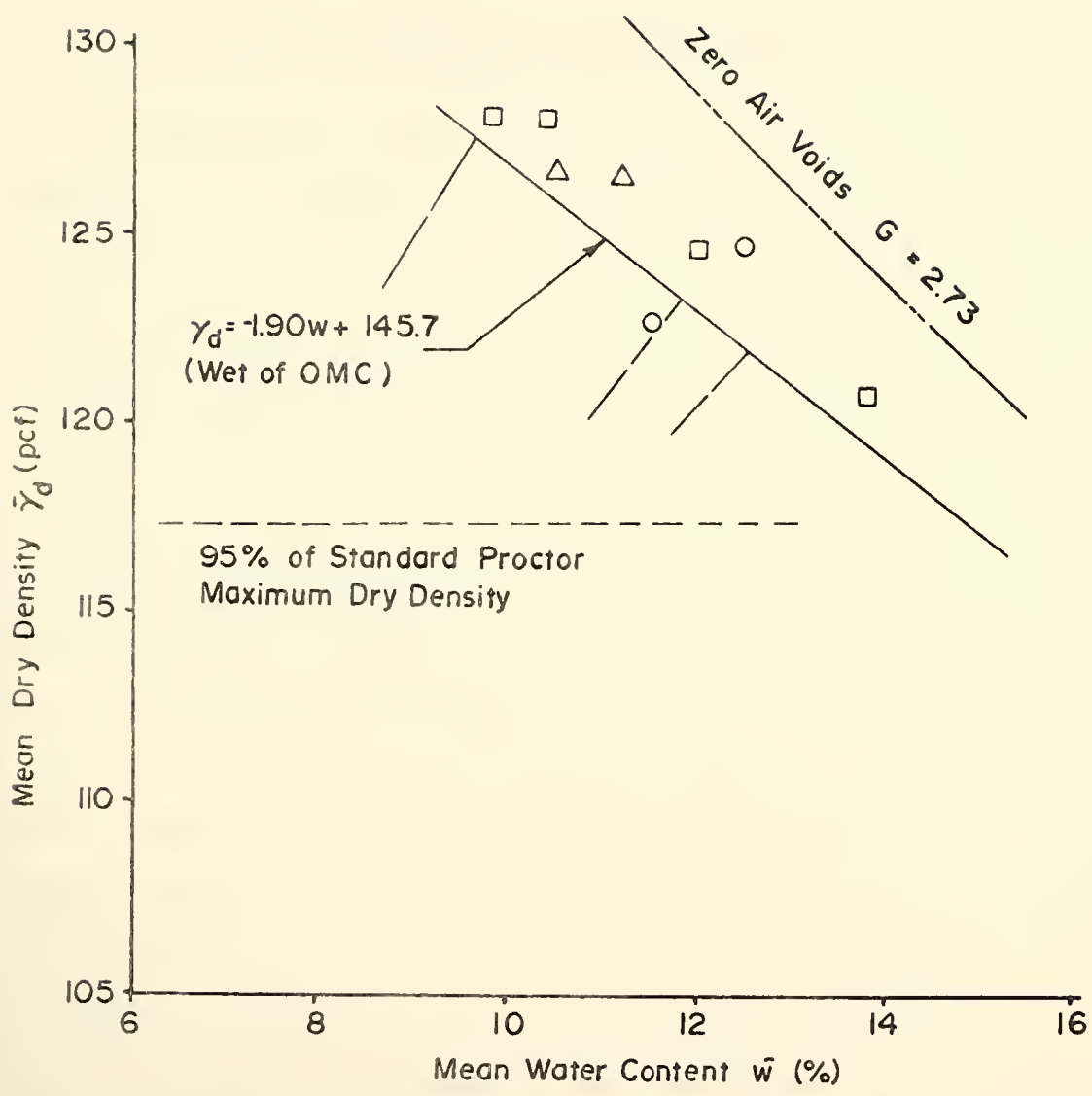

FIGURE 10 COMFARISON OF MOISTURE-DENSITY RELATIONSMIPS FOR FIELD AND LABORATORY COMPACTION. 
of compaction equipment he had available, was having no difficulty meeting the required compaction specification, even though the "Iow energy area" samples were taken from a lift which was determined by the inspector as unacceptable.

\section{Magnitude of Compressive Strength}

The regression results indicate that the magnitude of the shear strength in the laboratory can be described with a relationship consisting of the dry density and interaction between dry density and moisture content for all ranges of moisture content considered. The energy variable does not appear in the regression equation, but it is implicit in the dry density relationship for densities dry of the optimun moisture content. The regression relationship and mean value data are show in Figure 11. The statistical relationship seems to fit the data very well for the two lowest energies, but deviates somewhat for the higher energies. By comparing Figures 8 and 11, it appears that the maximum strength for any encrgy level is reached at about $1 \%$ dry of the optimum moisture content; the measured strength then decreases as the moisture content increases or decreases. The decrease in strength with decreasing moisture content is greater with increasing energy. Since the dry density relationship 

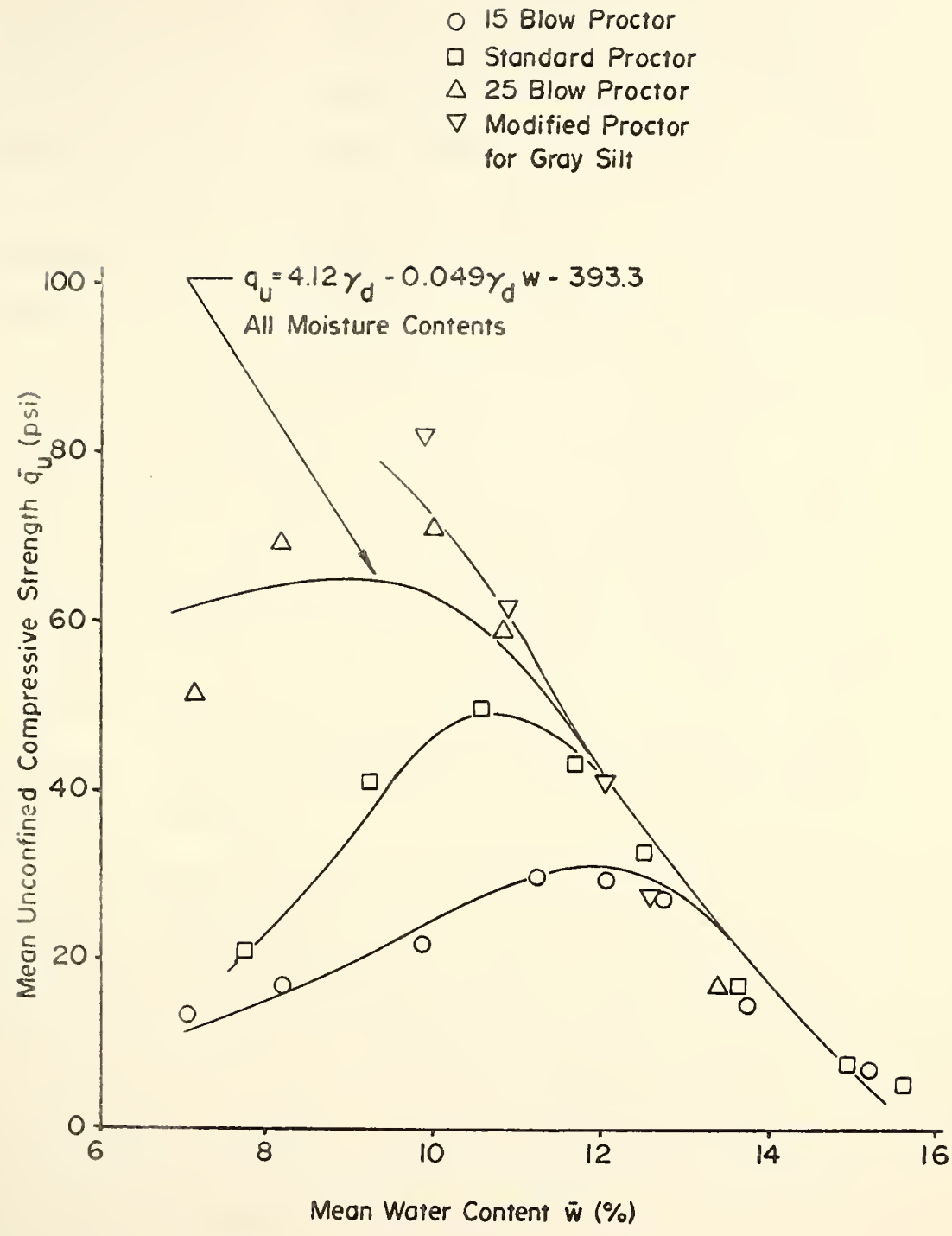

FIGURE II MOISTURE-STRENGTH RELATIONSHIPS FOR LABORATORY COMPACTION. 
for compaction wet of optimum moisture content is linearly related to moisture content, the strength regression could be rewritten in this region, substituting the density relationship, and describing strength as a function of linear and second order moisture contents only. From the all-possible regression results, Table 8, this relationship is very significant.

The strength regression relationship indicates that for a constant dry density, increasing the moisture content will decrease the strength for all levels considered. For a constant moisture content, the relationship between density and strength is not as easily aetermined from the regression relationship. In general, increasing the density will increase the strength. Both of these observations are consistent with the literature.

The strengths of the Standard Proctor and Harvard Miniature samples appear to be very similar. Figure 12 shows that the strength results compare quite favorably for high moisture contents, but some scatter seems to exist for the lower moisture contents. It was noted earlier that the moisture density relationships for these two compaction methods were quite similar. This would seen to indicate that the strength measured is relatively independent of the compaction method, at least for the two methods used here. That is, 

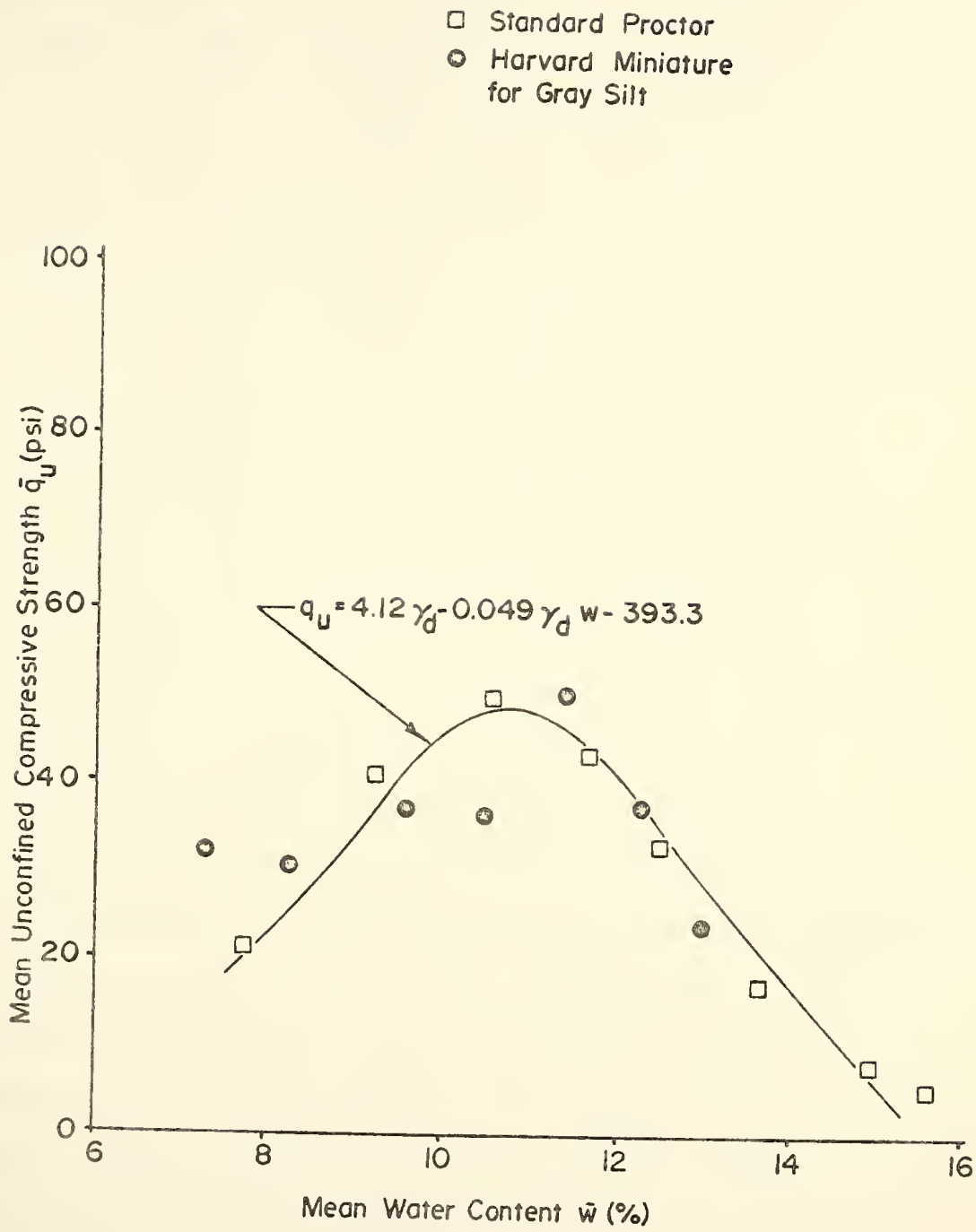

FIGURE 12 COMPARISON OF STANDARD PROCTOR AND HARVARD MMNATURE MOISTURE-STRENGTH RESULTS. 
similar moisture density results will produce similar strengths, independent of the method of compaction.

Figure 13 shows a comparison of the strength results for soils compacted in the field and laboratory. While it appears that no laboratory strength relationship is identical to the field relationship, the two sets of data appear very similar in trend. Since the location of the field dry density data in Figure 10 indicated that the equivalent field compaction energy was very high in relation to the laboratory efforts used, we would expect a high strength for the field compacted samples. The field strength results do not support this conclusion. The strengths measured in the field fall between the 15 blow and Standard Proctor laboratory strength curves, indicating that perhaps the field compacted strength relationship is less sensitive to dry density than is the laboratory relationship.

The regression relationship developed in the laboratory for the unconfined strength was a function of the dry density and the interaction between the density and moisture content. Using this relationship as a "prediction equation", with the measured rield densities and moisture contents, comparisons can be made between the predicted and measured strengths. Figure 14 was developed in this manner. From Figure 14, it can be seen that the predicted strength is almost always 
- Low Energy Areo

- Intermediate Energy Area

$\triangle$ High Energy Areo

for Groy Silt

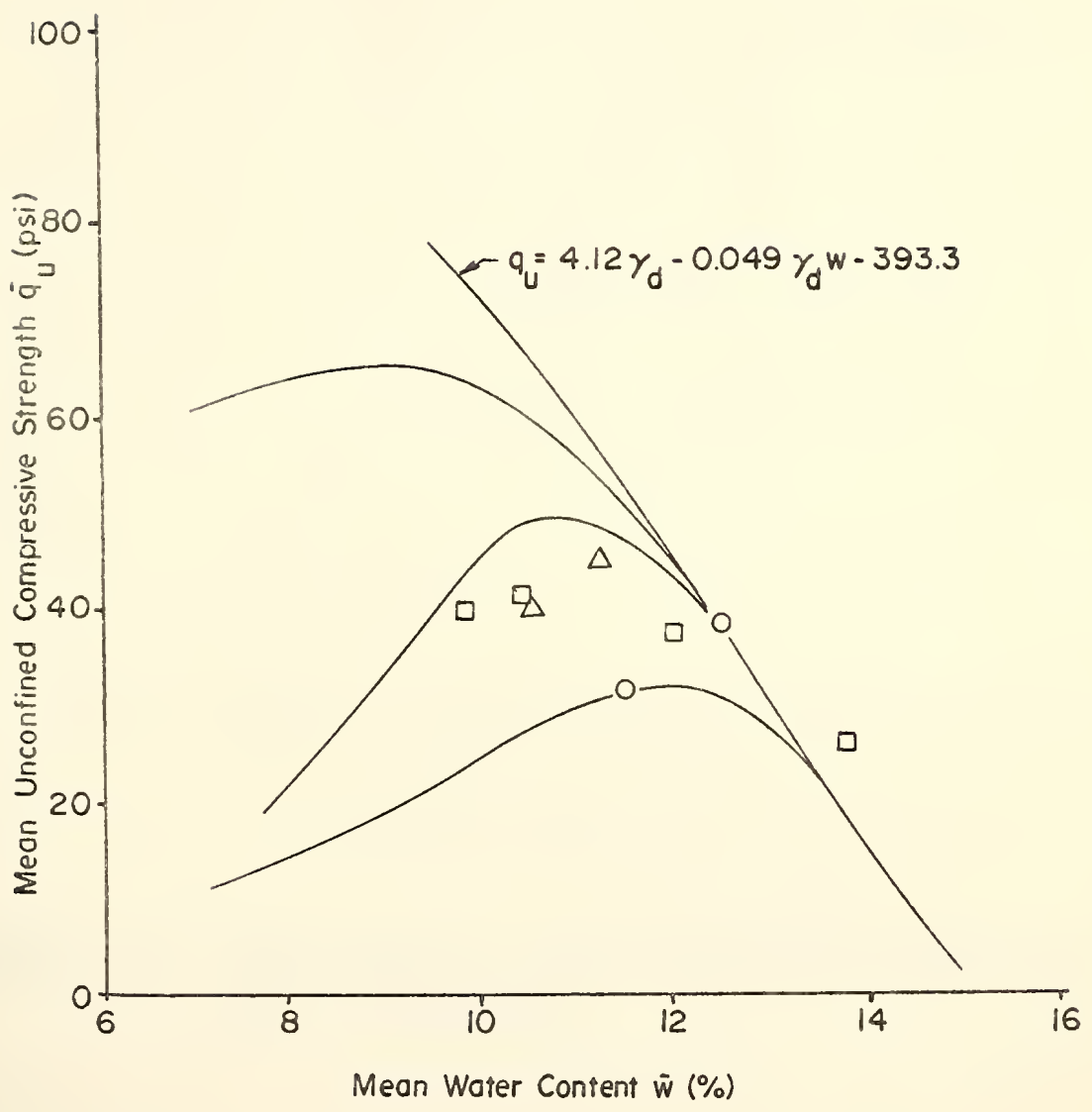

FIGURE 13 COMPARISON OF MOISTURE-STRENGTH RELATIONSHIPS FOR FIELD AND LABORATORY COMPACTION. 
- Low Energy Areo

口 Intermediate Energy Area

$\triangle$ High Energy Area

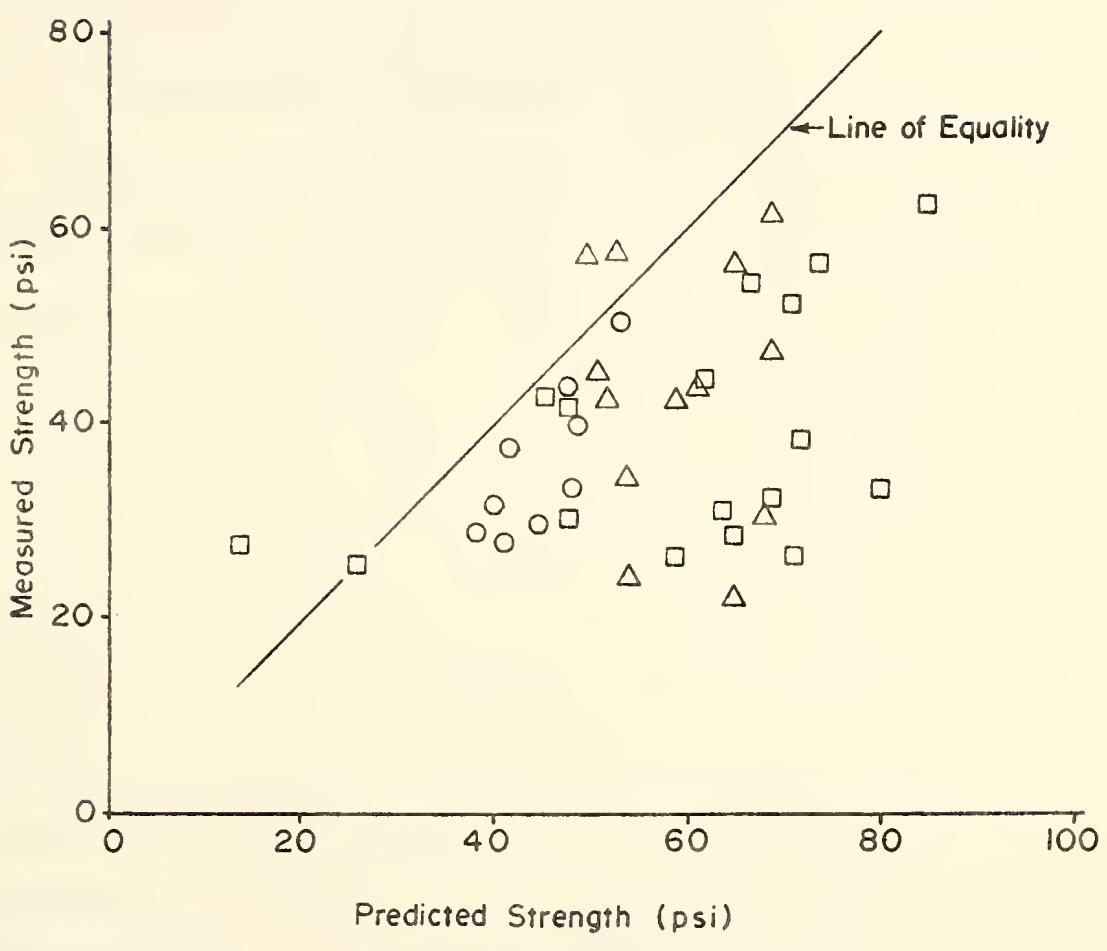

FIGURE 14 COMPARISON OF MEASURED AND PREDICTED FIELD STRENGTHS. 
greater than the measured. If the variability were not so large for this data, a regression could be performed between the predicted and measured strengths, similar to that developed by Peterson (1975).

\section{Magnitude of Dry Density Variability}

The statistical analysis shows that a rather complex function is required to describe the observed variations in ary density in the laboratory for the entire range of moisture contents. Because of this fact, it was again deciaed to treat the data wet and dry of the optimum moisture content independently.

The magnitude of the variations for samples compacted dry of optimum is a function of water content, dry density, and the interaction between the water content squared and the dry density squared. For compaction wet of optimum, the observed variation is explained by the interaction between water content and compaction energy. The statistical relationships for the variation in dry density and the observed laboratory variations are show in Figure 15. While the regression analysis indicates that the compaction enerey is not a significant variable in explaining the observed density variations dry of optimurn, energy is significant in explaining the magnitude of dry density in this 


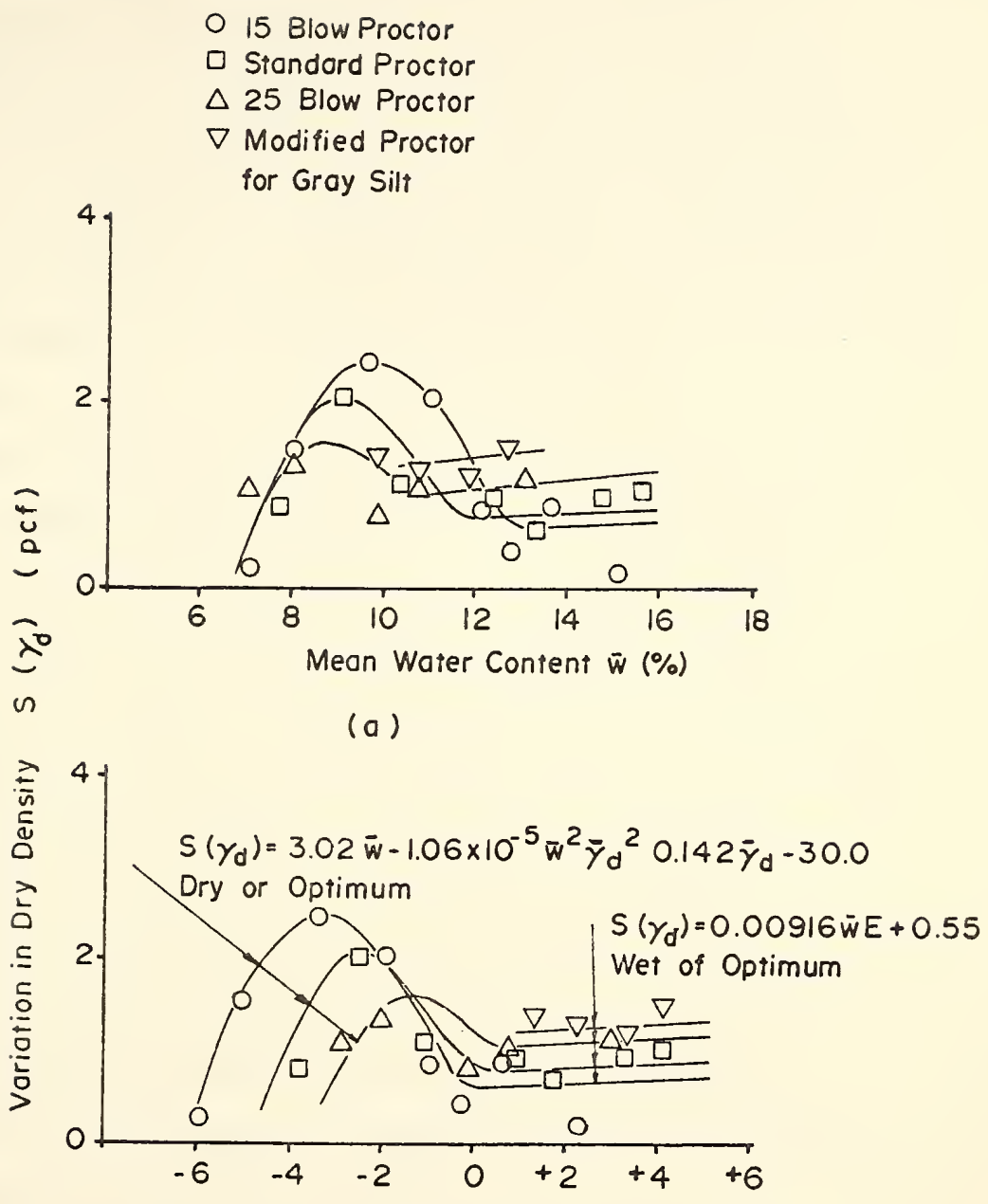

Deviation from Optimum Water Content $\Delta \bar{w}(\%)$

(b)

FIGURE 15 MOISTURE-VARIATION IN DENSITY RELATIONSHIPS FOR LABORATORY COMPACTION. 
moisture range. Therefore, energy is a significant variable even though it does not appear directly in the regression analysis. The statistical relationship for the variations in the wet of optimum moisture content range are a function of the moisture content and energy interaction variable. Therefore, the variation in density is affected by the compaction energy for all moisture contents.

Figure 15(b) shows that the variations with respect to the optimum moisture content for each energy level. For moisture contents less than the optimum moisture content (negative $\Delta w$ ), increasing the effort will decrease the amount of variability present. This trend continues to a moisture level that is about $1 \%$ less than optimum moisture content. At this point, all the variations are equal for any energy level used. It is also at this point that the energy effect markedly changes. From a moisture level just dry of optimum to the highest moisture content content considered, increasing the energy will slightly increase the amount of variation in density present.

The dry density variation seems to follow the trends indicated by the aggregate theory of Hodek(1972). . For very low moisture contents (well dry of the optimum moisture content), the soil aggregates present will be very small and very brittle. Densification will occur 
from rearranement and gracturing of the aggregates, and the packing will be quite independent of energy. The soil at this moisture level will still be principally in a ary "powdered" state. Increasing the moisture content (to near optimum) will tend to increase the size of the aggregates and because of these large sise and relatively rigid aggregates, the tendency for large inter-aggrectate voids will be prescnt. In this area, increasing the compactive energy will cause rearrangement and fracturing of the aggregates. With the initial existence of large voids comes the possibility for denser packing arrangements, and hence a larger range in nossible donsities can be expected. The addition of further water (past optimum) will further increase the size of the aggregate, but now, because of this higher moisture content, the soil aggregates become more plastic. Inergy will now cause densification by deforming the soil aggregates at essentially constant volume. Increasing energy in this region will essentially eliminate the pore snace between the aggregates. All of these trends are show in Figure 15.

The Harvard Miniature density variations are quite similar, in both magnitude and trend, to the density variations of the Standard Proctor compaction method. Figure 16 shows this similarity. The Harvard Miniature 


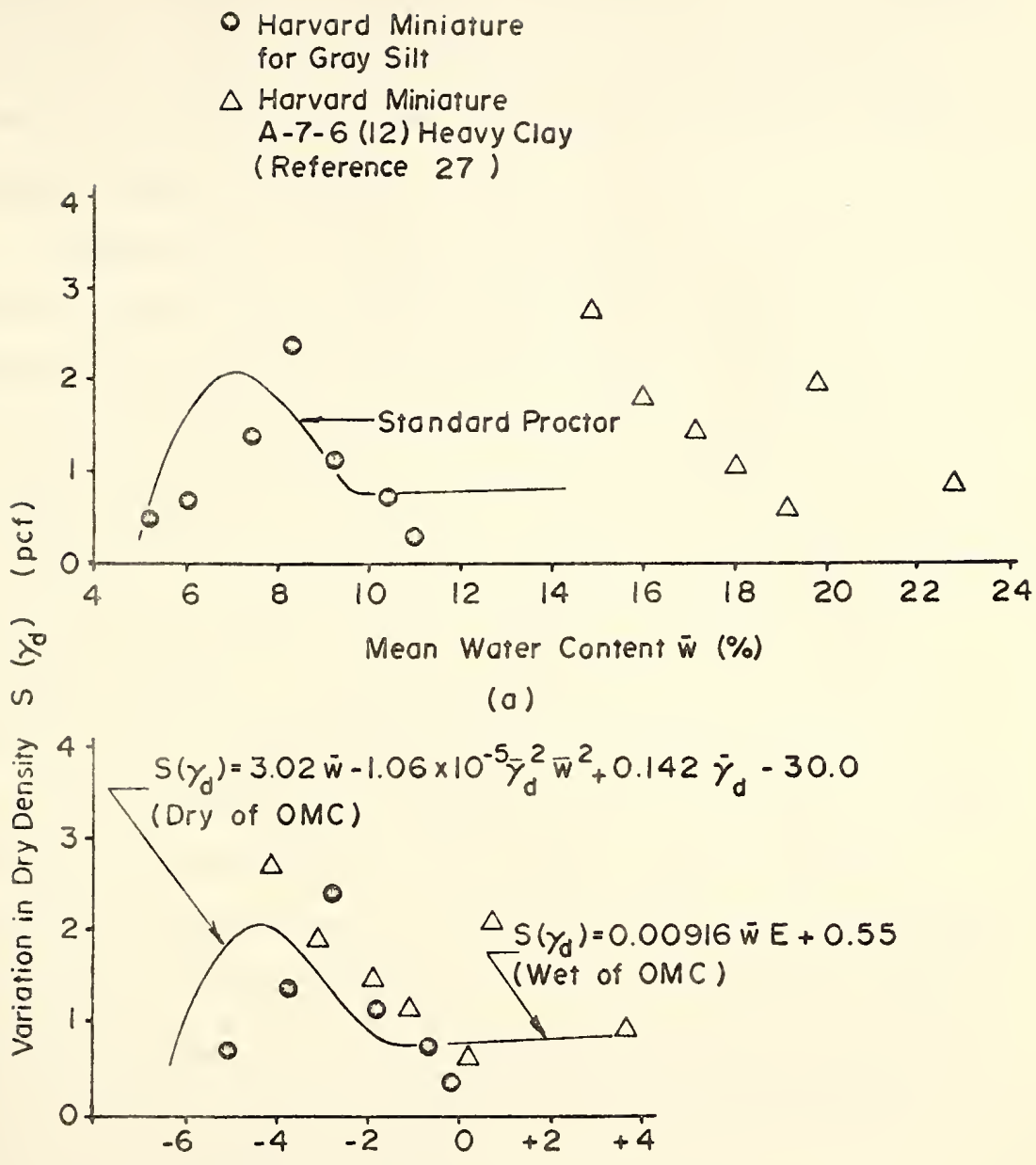

Deviotion from Optimum Woier Content $\Delta \bar{w}(\%)$

(b)

FIGURE 16 COMPARISON OF STANDARD PROCTOR AND HARVARD MINIATURE VARIATION IN DENSITYMOISTURE RELATIONSHIPS. 
results seem to be shifted slightly toward the higher moisture contents in Figure 16(b); that is, the maximum deviation occurs much closer to the optimum molsture content for this method of compaction than any of the impact energies studied.

The trends established exist for solls other than those studied in this laboratory testing program. Figure 16 also shows results found in the literature. Mitchell (1955) published results of a laboratory compaction program using the Harvard Miniature compaction apparatus for a heavy clay. Figure 16(a) shows that the the deviation results are shifted far to the right (higher moisture contents), which is to be expected with the more plastic clay used. However, when the data are referenced to optimum moisture content (Figure 16(b)), the comparison is very good. The published Harvard Miniature results fall very close to the Harvard Miniature results generated in this laboratory program. Other published data were considered for analysis, but since a great deal of data is required, no specific conclusion could be drawn.

The field variations measured for the gray silt are quite similar to the variations produced in the laboratory, although somewhat larger. Figure 17 is a comparison of the variations in density for the field and laboratory. While the variations appear quite 


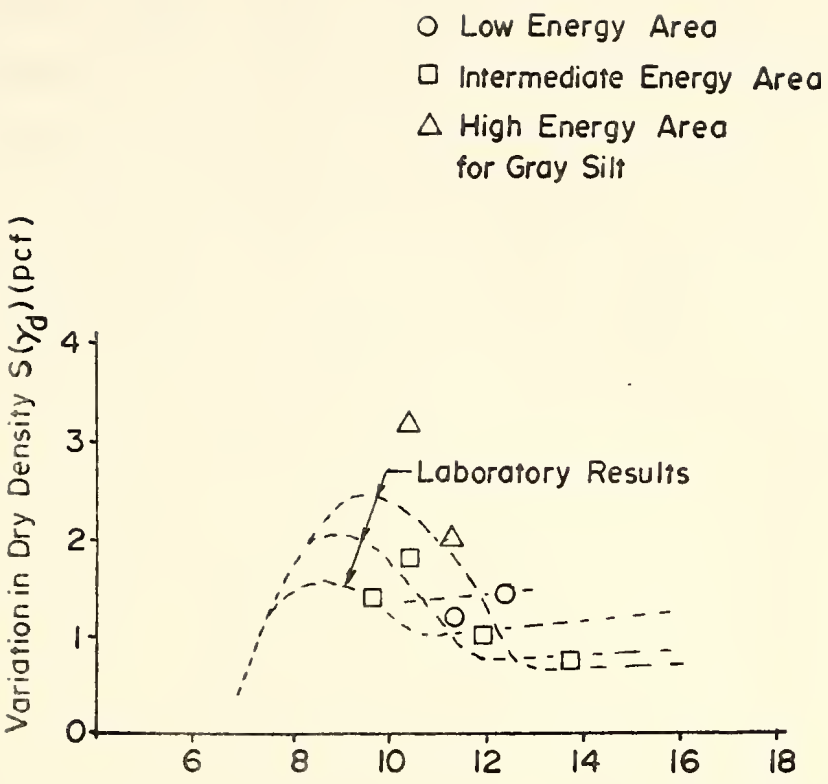

Mean Water Content $\bar{w}(\%)$

FIGURE 17 COMPARISON OF MOISTURE-VARIATION IN DRY DENSITY FOR FIELD AND LABORATORY COMPACTION. 
similar, no positive trenas can be established because of a lack of sufficient data and the inability to quantify the energy level for field compaction.

As part of an earlier phase of this study (Peterson, 1975), data were collected from ISHC construction records. These data consisted of numerous density, moisture content and energy levels for several soil types and varieties of compaction equinment. In many cases, a sufficient quantity of data was not available to break up into one percent moisture subsets as done for the laboratory and field data generated in this study. However, several trends can be roughly established from these data. Referring to Figure 15, if all the variation in dry density data were averaged over all moisture contents used, then, as the enerry increased, the average varlation would tend to decrease. This observation should hold true if the field data considered are over nearly the same range in moisture contents, and the data considered are not from the wet side of optimum only. Figures 18(a) and 19 show ISHC data considered this way. Since the data were generated under actual construction conditions and the energy listed on the control records for compaction is probably not exact, considerable scatter is to be expected. However, the data do generally indicate a trend. 


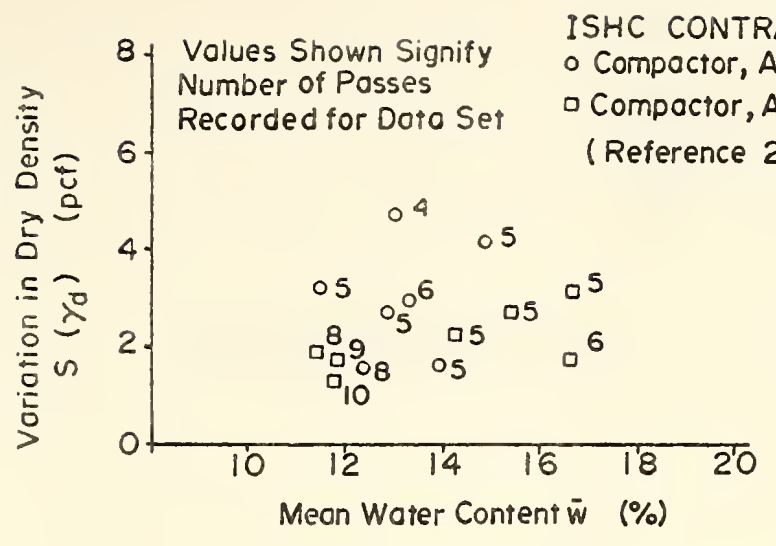

(a)

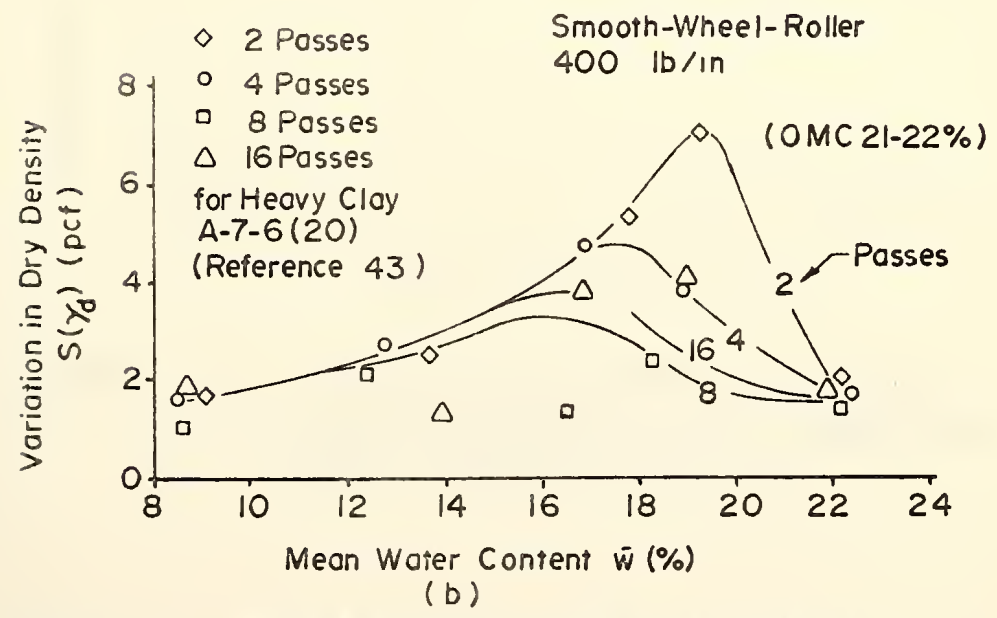

FIGURE 18 MOISTURE-VARIATION IN DENSITY RELATIONSHIP FROM PUBLISHED DATA. 
ISHC Contract 8757

O Vibratory Roller

$\square$ FWD Roller

$\triangle$ Sheepsfoot Roller

All for A-6 Soil

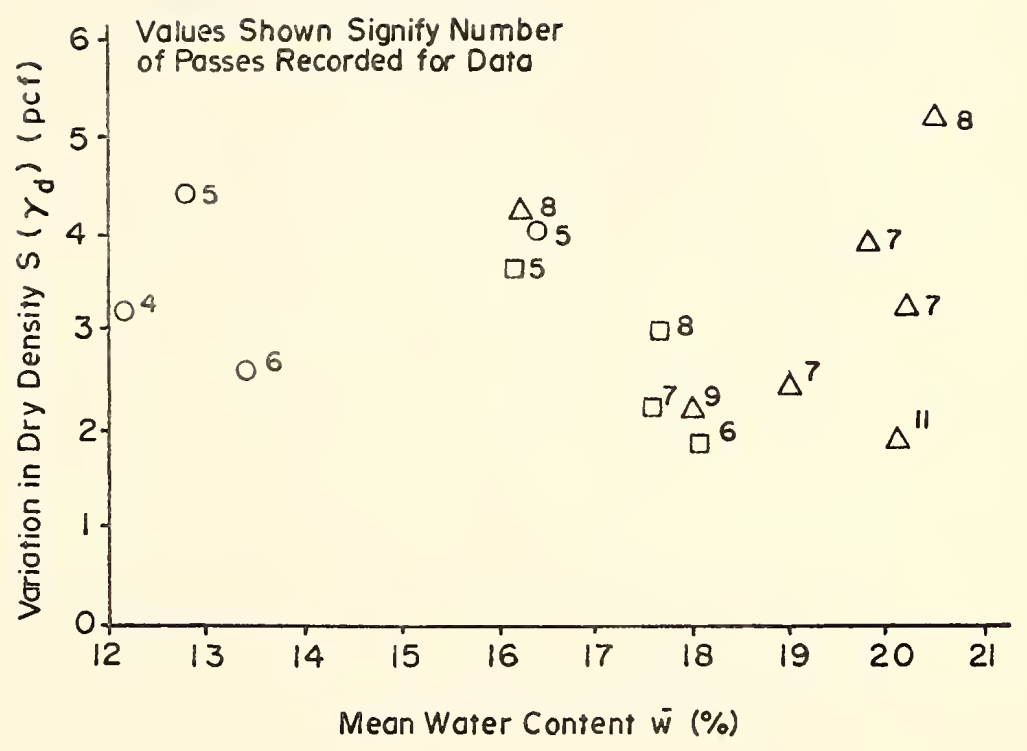

FIGURE 19 MOISTURE-VARIATION IN DENSITY RELATIONSHIP FOR ISHC CONTRACT 8757 (REFERENCE 29 ). 
The examination of other published field studies reveals that, if sufficient control procedures are exercised, results of the variations proauced are quite similar to those observed in the laboratory. Published studies by the Australian Road Research Board (ARRB) (Mynan and Morris, 1968) for compaction on a heavy clay are show in Figure 18(b). The data shown here (unfortunately the studies were only for compaction dry of optimum) support the trends isolated in the laboratory; that is, decreasing variation in density with increasing energy for compaction in this moisture range. Other data published for ARPB studies support this observation, but not in such a consistent manner.

\section{Namitude of Comoressive Strenth Variability}

The variation in strength can be represented over the entire range of moisture contents considered by a relationship involving the actual magnitude of the shear strength and the corresponding variation in density at that strength level. The relationship developed for all moisture contents is equally valid for dry of optimum and wet of optimum compaction in the laboratory. An examination of the statistical relationship developed indicates that an increase in strength or an increase in density variation will cause an increase in the variation in strength. In 
fact, if there is no variation in density at all $\left(s\left(\gamma_{d}\right)=0\right)$, there will still be a considerable amount of strength variation present.

Figure 20 shows the predicted and the measured laboratory variations, both with respect to the absolute level of moisture content and with respect to optimum moisture content for each energy level. Figure 20(a) shows that the variation in strength is nearly independent of energy for high moisture contents; that is, the produced variations are nearly the same for each energy used for compaction in the laboratory. This results from the strength being nearly constant in this region, and a slightly increasing variation in density with increasing energy.

A comparison of Figures 15(a) and 20(a) reveals that, for compaction dry of optimum moisture content, the effort level with the highest variation in dry density (15 blow Proctor) has the lowest variation in strength. Since this lowest effort level level results in the lowest strengths, the relative importance of the shear strength and variation in dry density variables is illustrated. Therefore, for compaction at moistures ary of optimum, increasing the compaction energy will decrease the dry density variation, but will increase the shear strength variation. 


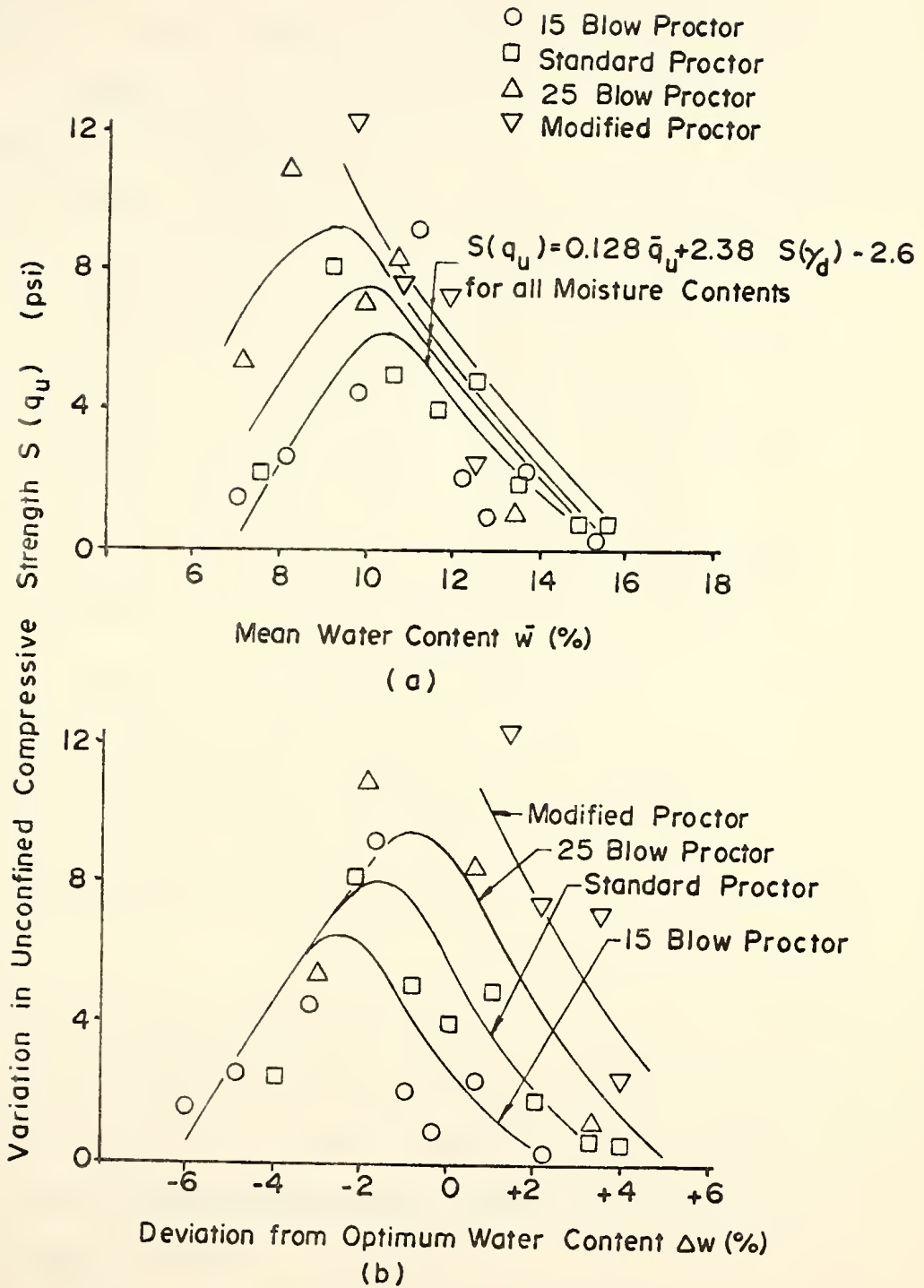

FIGURE 20 MOISTURE-VARIATION IN STRENGTH RELATIONSHIPS FOR LABORATORY COMPACTION. 
Pigures 11, 15(b) and 20(b) show that the maximum strength variation occurs at the moisture content where the variation in density and mean value of strength are at the maximum.

The Harvard Miniature compaction data for the gray silt shown in Figure 21 again agree closely with the Standard Proctor variations in trend, but are shifted somewhat in position (for both absolute moisture levels and with respect to OMC). From all the Harvard Miniature data considered in this study, it would appear that the magnitudes of the variations produced (both in density and strength) are similar to those for the Standard Proctor impact method, but are "skewed" somewhat in relative position. This would indicate that these two methods of compaction produce the same variations, but the kneading compactor moves the maximum variations closer to the optimum moisture content.

Pigure 21 also shows the results of Mitchell (1955). As with the density variation data, the values measured are shifted toward the higher moisture contents because of the higher plasticity characteristics of the clay. However, when the data are compared with respect to optimum moisture content, fair agreement with the other data is evident, especially for moisture contents greater than optimum. 


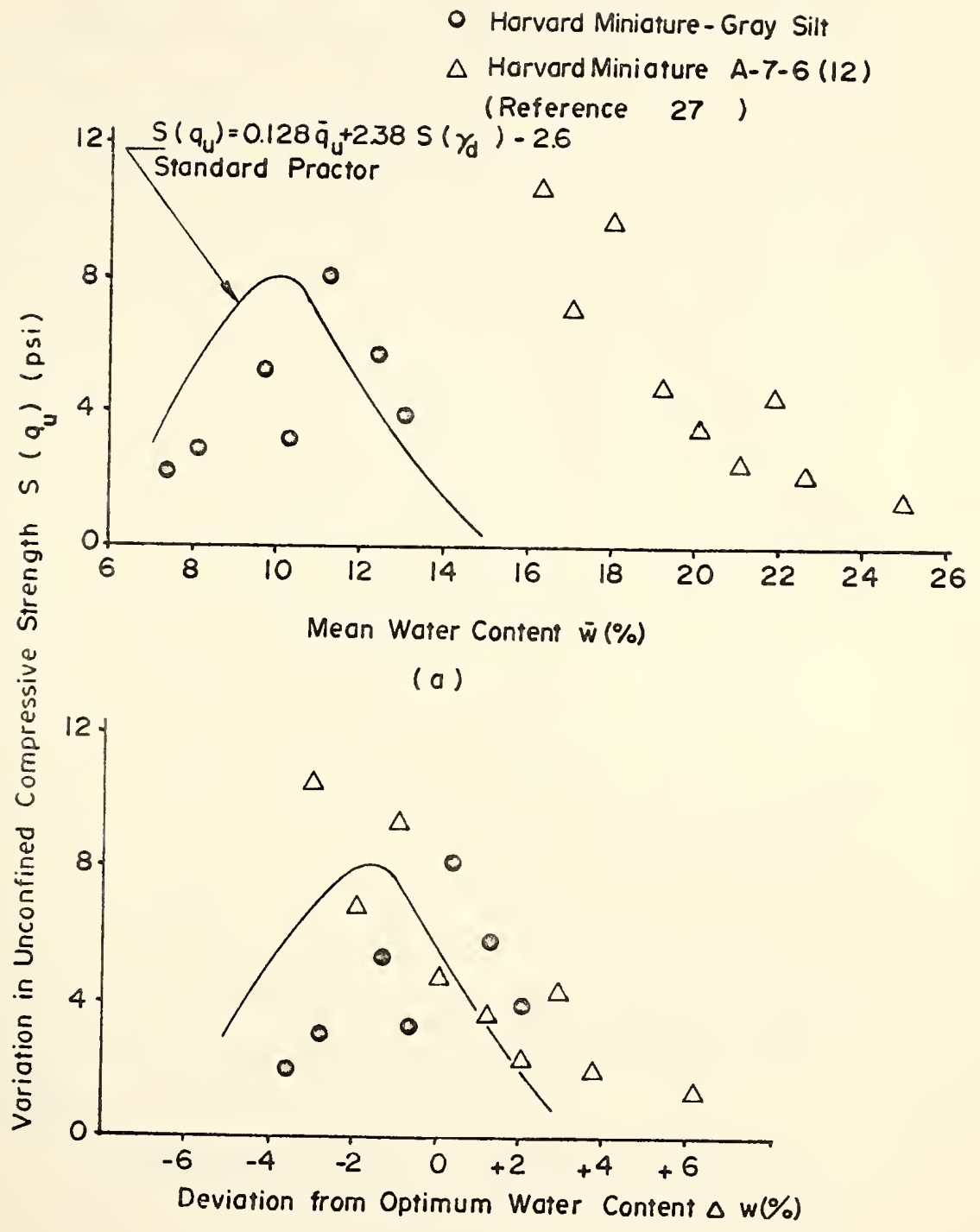

(b)

FIGURE 21 COMFAFISON OF STANDARD PROCTOR AND HARVARD MMNIATURE MOISTURE VARIATION IN STRENGTH RELATIONSHIPS. 
It would appear from Figure 22 that the variation in strength produced at the same moisture contents by the field compaction method is much greater than in the laboratory. Since the field strengths were lower than those in the laboratory at the same moisture and density comoination, the higher field variations in strength results in a much higher coefficient of variation (COV) in strength. The COV for laboratory compaction ranged from 0.03 to 0.20 , vinile the field COV in strength ranged from 0.05 to 0.40 (see Figure 23). It would also appear that, as shown in Figure 22, the amount of field variation produced is very sensitive to small changes in moisture content. Whe measured field variations vary from 1.5 to 18 psi over only a small range of $4 \%$ moisture content. These variation differences may be a result of the different methods of sampling used in the laboratory (hydraulic jack) and in the field (drop hammer). As noted by Lumb (1966), the sampling method can produce an increase in the coefficient of variation, partly because of the sampling disturoance produced.

\section{Variability Resulting From Soil Compaction}

Much work dealing with the variability of pavements and input variables has been done by researchers in the pavement design areas (Kennedy, Hudson, McCullough (1975) discussed this area in detail). Hudson (1975) discusses 


\section{- Low Energy Areo \\ 口 Intermediote Energy Areo \\ $\triangle$ High Energy Areo for Gray Silt}

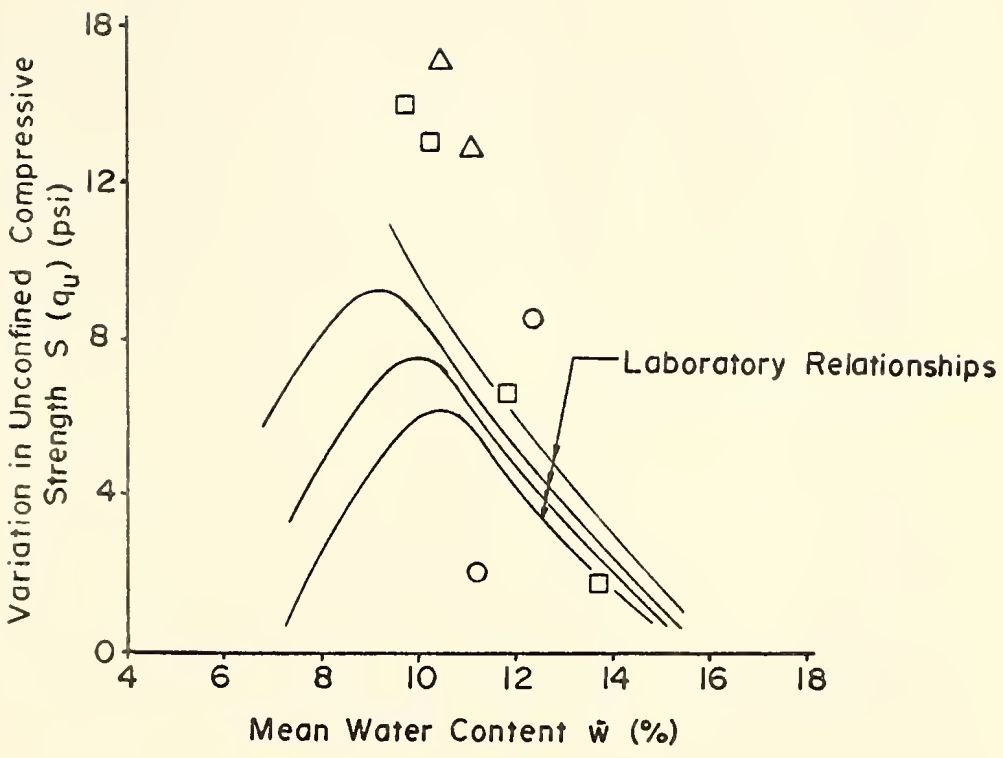

FIGURE 22 COMPARISON OF MOISTURE-IARIATION IN STRENGTH RELATIONSHIP FOR FIELD AND LAEORATORY COMPACTION. 


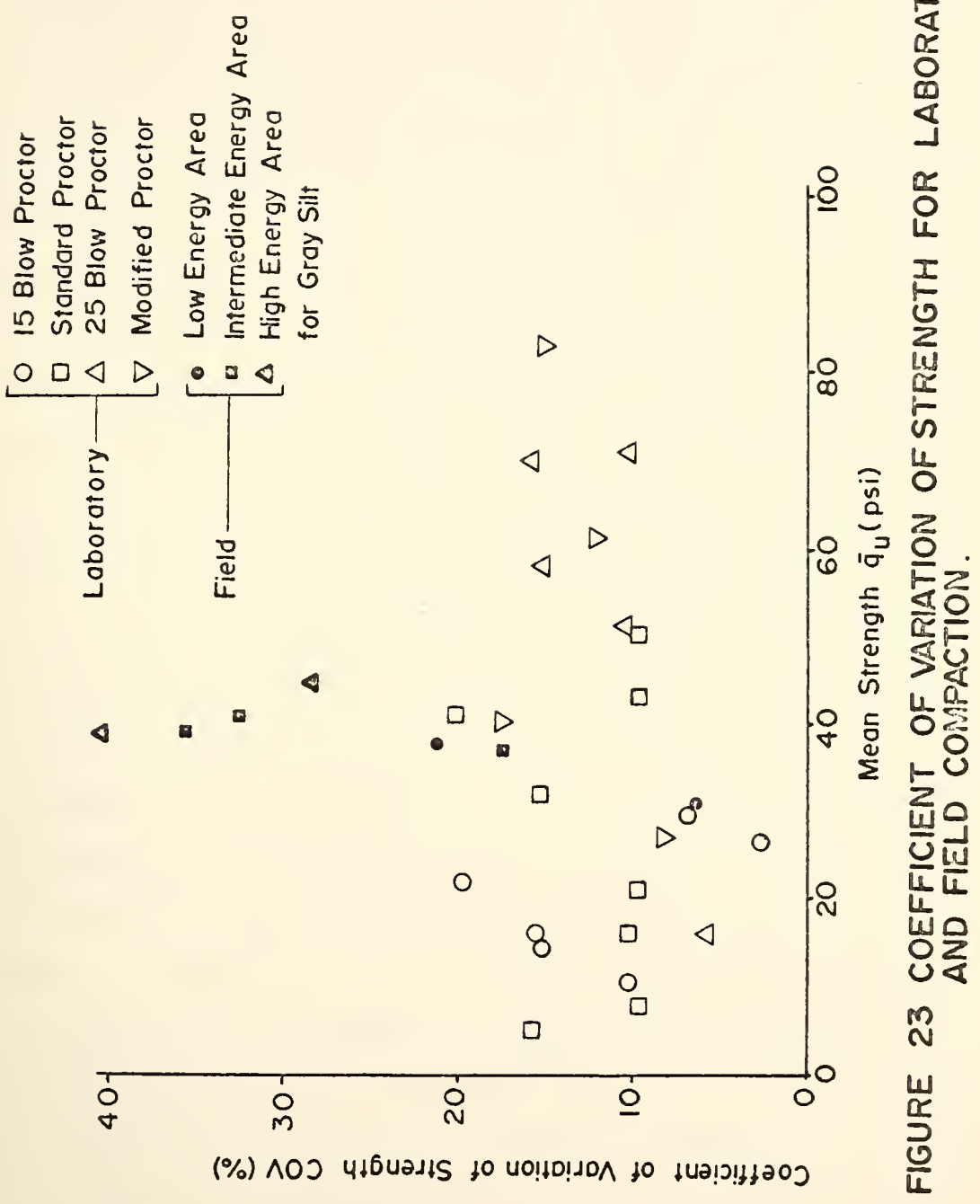


the concepts of reliability and how they relate to pavement design moảel reliability, materials reliability, load variability and actual pavement performance. Hudson presents a design nomograph which includes among other things, a scale for the "overall variance" determined by the level of quality control exercised, variations associated with design parameters and errors associated with traffic predictions.

The statistical analysis indicates that a nomographic type solution would be a convenient method of combining the results of all the individual analyses performed in this study. Figure 24 is the resulting combination of the statistical results. If it were desired to compact a soil such that the resultant mass would have specified strength properties, the nomograph could be used to isolate regions of moisture and density where the measured strength would be as desired and allow for the variations inherent in the process. The nomograph was developed from the laboratory relationships, rather than the field data. However, since many of the field relationships are quite similar to these produced in the laboratory, it should be possible to construct such a diagram for field compaction if sufficient, carefully controlled data were available.

The nomograph was constructed using the mathematical relationships developed earlier, and shown in Table 10. 
(1)

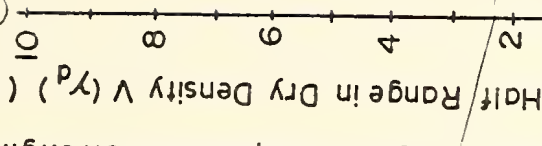

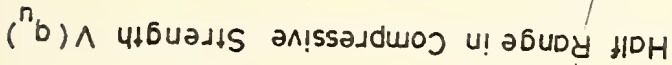

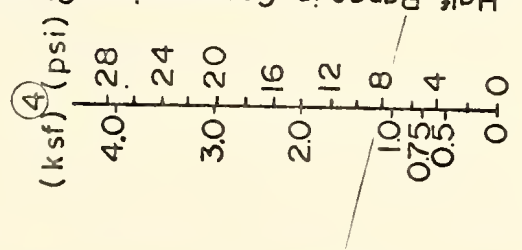

nb 4!buaj!S an!ssaddwoj pau!juojun UDaW

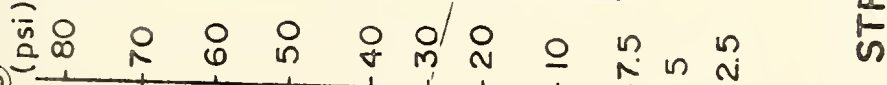

$$
\begin{aligned}
& \text { (i) }
\end{aligned}
$$

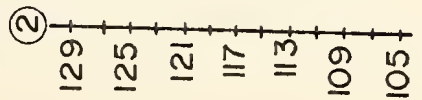

$\sum_{0}^{I}$

융

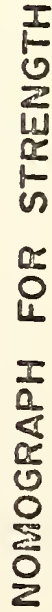

๙

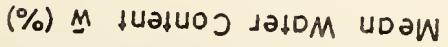


However, rather than using the variation in dry density and strength, $s\left(\gamma_{d}\right)$ and $s\left(q_{u}\right)$, these values were converted to one half the range in density and strength, $v\left(\gamma_{\dot{\alpha}}\right)$ and $v\left(q_{u}\right)$ using the following relationships:

$$
\begin{aligned}
& v\left(\gamma_{d}\right)=2 s\left(\gamma_{d}\right) \\
& v\left(a_{u}\right)=2 s\left(q_{u}\right)
\end{aligned}
$$

Since statistical theory for a normal distribution indicates that approximately 95\% of all data will fall in a region bounded by the mean value plus or minus two standard deviations, a four standard deviation width is seen to be approximately equal to the range in values expected.

The nomograph can bc used to establish areas of moisture and density where the desired strength properties are present. For example, if a laboratory compacted soil was required, with a mean unconfined compressive strenoth $\left(\bar{a}_{u}\right)$ of 30 psi, the use of scales one, two and three, Figure 24, indicate that this mean strength can be obtained at moisture-density combinations of 8\%-113.0 pef, 11\%-118.5 pef and 14\%-123 pef, among many other possible combinations. Using the three moisture-density points, a line of constant mean strength (line RS in Figure 25) can be established. The variation in strength is a function of the mean strength and variation in density. Scales three, four and five can be used to establish an "allowable" range in dry density; this 


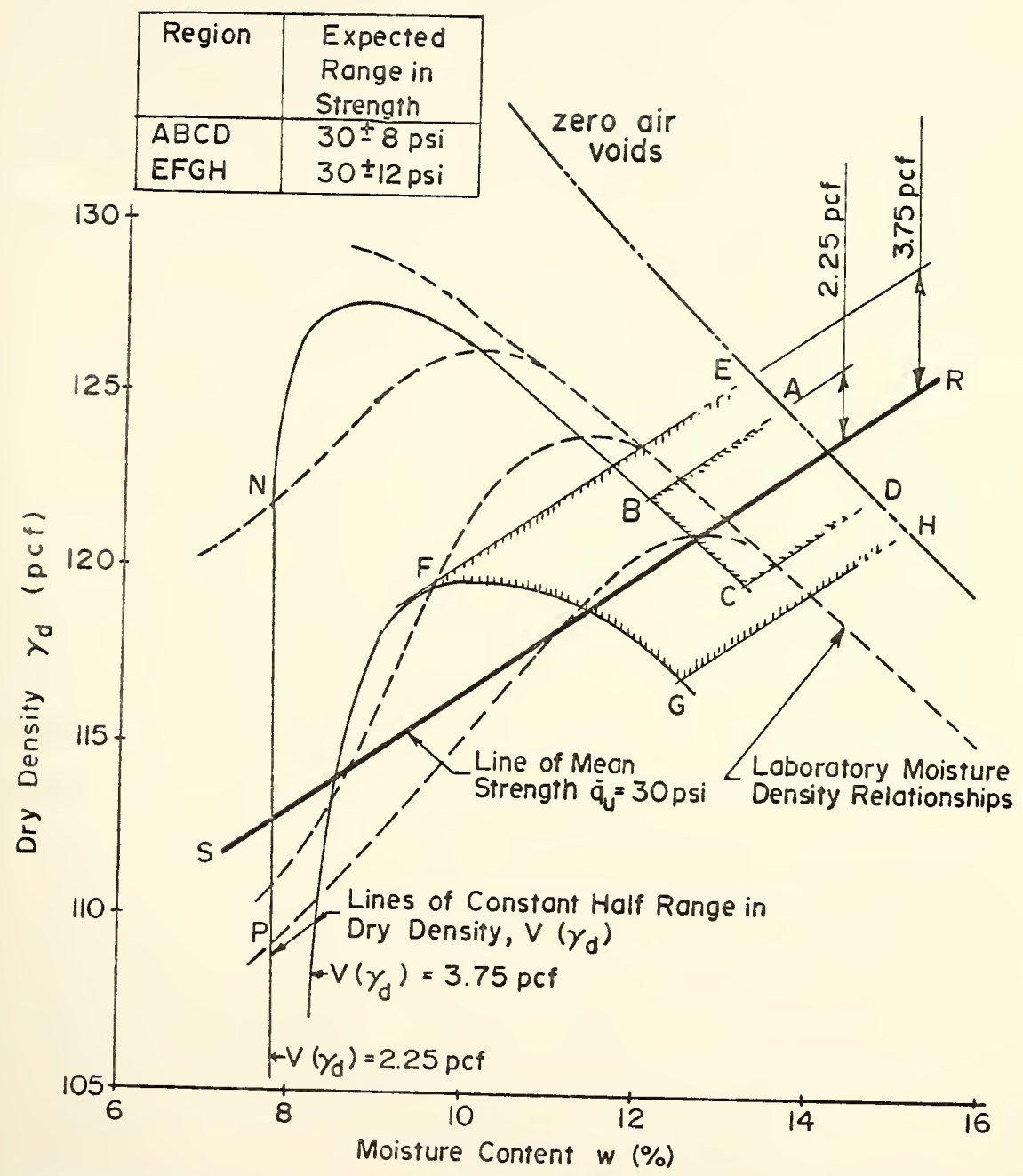

FIGURE 25 ACCEPTABLE MOISTURE-DENSITY REGIONS FOR DESIRED STRENGTH AND STRENGTH VARIABILITY. 
range in density will insure that the measured strength results fall within the acceptable specified tolerances. If the desired variation in strength is to be \pm 8 psi $\left( \pm v\left(q_{u}\right)\right)$, then the allowable range in density is \pm 2.25 pcf $\left( \pm v\left(\gamma_{d}\right)\right)$. That is, the densities must fall within the area of line RS plus or minus 2.25 pef as indicated by Iines $A B$ and $C D$ in Figure 25. This variation in density is not possible at all moisture contents. Moisture content regions must be isolated where this range in density is possible. Through the use of scales five and siz: of the nomograph, lines of constant variation in dry density can be established. Iine CBNP (Figure 25) is the line generated from the nomograph where a constant half range in dry density of 2.25 pef can be cbtained. The shaded region ABCD (Figure 25) has now been isolated, and within this area the strength will be the required $30 \pm 8$ psi.

The size of this "specification region" is determined by the range in accentable strengths. If a larger range in strengths is accentable, then the size of the acceptable region will increase. This is shown by region EFGH (30 $\pm 12 \mathrm{psi}$ ) in Tigure 25. This region was developed through the use of the nomograph as explained earlier. A nomograph similar to Figure 24 should be possible for field compaction. Closely controlled field studies would yield the necessary field data to determine the field functional relationships. If further field compaction 
studies indicate that the same variables are significant in the field as in the laboratory, then the nomograph (Figure 24) will remain essentially unchanged. A shift in the horizontal spacing of the scales, as well as their size, would account for the differences between the field and laboratory.

Since the type of compactive effort is recognized as an important variable, scales five and six would be for only one type of field compaction, but at various effort levels. This might then require various nomographs, one for each type of compactive effort (sheepsfoot rollers, mober-tire rollers, vibratory rollers, etc.), unless the type of effort variable could also be quantified.

If a nomograph of the type indicated in Figure 24 were developed for field compaction, the designer could specify the strength properties he requires in the compacted mass. By stating the strength his design will require, as well as the strength variability he is willing to accept, then plots similar to Figure 25 could be produced to isolate areas of moisture and density within which he must compact to insure the properties he desires. 


\section{CONCLUSIONS}

This study examined statistically the relationship between laboratory (impact) and field (tamping foot roller) compaction for one glacial silty-clay soil. Within the constraints established for this project, the following conclusions can be made:

1) The minimal amount of field compaction data that was available and could be easily gathered without special controlled procedures did not allow a statistically meaningful correlation to be developed between laboratory and field compaction results.

2) The data collected for the field compacted soils appear very similar in trend to the relationships developed in the laboratory; however, the variability associated with the field compaction seems to be larger than that associated with compaction carried out in the laboratory.

3) It would appear that meaningful forecasts of field compaction results are available from laboratory test results if sufficient closely controlled field data were available for the initial correlation. 
4) For soils compacted in the laboratory, the following relationships are statistically significant:

a) The most important variables controlling the as compacted dry density are the moisture content and the interaction between the moisture content and compaction energy.

b) The most important variables controlling the as compacted shear strength are the dry density and the interaction between dry density and moisture content.

c) The most important variables controlling the as compacted variation in dry density are the moisture content, dry density, and interactions of moisture content with energy and moisture content with dry density. Increasing the compaction energy will tend to decrease the dry density variability.

d) The most important variables controlling the as compacted variation in shear strength are the shear strength and the variation in dry density. Increasing the compaction energy will tend to increase the variation in shear strength. 
RTCOMMENDATIONS FOR FURTHER STUDIES

1. Further work is necessary to provide correlations between the laboratory and field. Valid statistical predictions of field performance should be available if sufficient controlled data is available for the initial correlation.

2. The relative importance of the field compaction variables should be evaluated to determine where tighter controlls are needed in order to remove the large amount of variability present in the compacted mass.

3. The relative importance of the variables in controlling the in-service performance should be evaluated. Studies should evaluate the saturated strengths, both for the laboratory and field compacted samples.

4. Performance properties other than the unconfined strength should be studied. Relationships for the failure strains, moduli, swell and collapse potential, etc., should be studied. 


\section{ACKNOWLEDGMENTS}

The author is grateful to the Joint Highway Research Project of Purdue University, the Indiana State Highway Commission, and the Federal Highway Administration for their financial support of the study.

The author wishes to express his appreciation to Professors A. G. Altschaefel and C. W. Lovell for their assistance and guidance throughout the course of this project.

Thanks are due Professor V. L. Anderson for his advice concerning the statistical aspects of this study, and to Mr. Dan Rand, statistical consultant to the CE Staff, for his help in the analysis of the data.

Special thanks are due Mr. John Peterson and Mr. James Scott for their assistance in generating and analyzing the project data. 
BIBLIOGRAPHY 


\section{BIBIIOGRAPHY}

1. Ahmed, S. (1971) "Pore Size Distribution and its Effect on the Behavior of a Compacted Clay," NSCI Thesis, Purdue University, West Lafayette, Indiana, June, $200 \mathrm{pp}$.

2. Belcher, D.J. (1941) "A Field Investigation of Iow-Cost Stabilized Roads," Research Series No. 81 Engincering Bxperiment Station, Purdue University, Vol. 25:2A.

3. Bhasin, R.N. (1975) "Pore Size Distribution of Compacted Soils After Critical Region Drying," Ph. D. Thesis, Purdue University, West Lafayette, Indiana, Iiay, $222 \mathrm{pp}$.

4. Bruzelius, N.G. (1954) "A Study of the Compaction of Soil," Statens Varinstitut, Medaelande 87, Stockholm, $74 \mathrm{pp}$.

5. Carey, W.N. Jr. (1957) "Discussion to paper Maximum Density and Noisture of Soils' by F.î. Haveem," Soil Density Control Methods, Hirhway Research Board Bulletin 159:20

6. Casagrande, A. and Hirschfeld, R.C. (1962) "Second Progress Report on Investigation of StressDeformation and Strength Characteristics of Compacted Clays," Soil Mechanics Series No. 65, Harvarà University.

7. Diamond, S. (1971) Microstructure and Pore Structure of Impact-Compacted Clays," Clays and Clay Minerals, Vol. 19, pp 239-249.

8. Fischer, C.P., Bridges, D.N. and James, T.G. (1962) Moisture and Density Measurements in Engineering Soils," Final Report, Project D, Hi ghway Research Program, Engineering Research Department, North Carolina State College, Raleigh, North Carolina. 
9. Highter, W.H. (1969) "Temperature Effects on the Compation and Strencth Behavior of a Clay," MSC Thesis, Purdue University, West Lafayette, Indiana, August, $83 \mathrm{pp}$.

10. Highter, W.H., Altschaeffl, A.G. and Iovell, C.W. Jr. (1970) "Low- Pemperature Effects on the Compaction and Strength of a Sandy Clay," Hishway Research Record No. 304, Highway Research Board, p. 45.

11. Hilf, J.W. (1959) "Compacting Earth Dams with Heavy Tamping Rollers," Transactions, ASCF, Vol. 124, pp. $409-435$.

12. Hillis, S.F. and Smith, D. (1967) "Discussion: 'Portage rountain Darn, II,' by G.C. Morgan and M.I. Karris," Canadian Geotechnical Journal, Vol. IV, No. 2, May, pp 175-178.

13. Hodek, R.J. (1972) "Mechanism for the Compaction and Response of Kaolinite," Ph.D. Thesis, Purdue University, West Iafayette, Indiana, December, 269 pp.

14. Hooper, J.A. and Butler, F.G. (1966) "Some Numerical Results Concerning the Shear Strength of Iondon Clay," Geotechnique, Vol. 16, No. 4, pp 282-304.

15. Hogentogler, C.A. and illis, E.A. (1936) "Stabilisation of Soil Roads," Public Roads, Vol. 17, No. 3, op 45-65.

16. Holtz, W.G. and Flis, W. (1964) "Comparison oI the Shcar Strengths of Iaboratory and Field Compacted Soils," ASTM, STP 361 , pp 471-481.

17. Hudison, R.W. (1975) "State-of-the-Art in Predicting Pavement Reliability from Input Variability," U.S. Army Ingineer Waterways Experiment Station, Contract Renort $\mathrm{S}-75-7$, August.

18. Ingles, O.G. (1972) "Statistical Control in Pavement Desisn, "Proceedings of the First International Conference on Annlications of statistics and Probability to soil and Structural incineering,

19. Ingles, O.G. (1974) "Compaction," New Horizons in Soil liechanics, I.K. Jee, Editor, American EIsevier Puolishing Company, Inc., New York, 286 pp. 
20. Johnson A.W. and Salberg, J.R. (1960) "Factors that Influence Field Compaction of Soils," Hi mhay Research Board Bulletin No. 272.

21. Johnson, A.i. and Salberg, J.R. (1962) "Factors Influencing Compaction Test Results," Highway Research Board Bulletin No. 319.

22. Johnson, M.M. (1969) "Laboratory Compaction Tests Using Compacted Fine Grained Soils," Ith International Conference on Soj.I Mechanics and Foundation ingineering Proceedines, Vol. 1, Mexico, pp $197-202$.

23. Jorร̆cnscn, J.I. (1969) "Measuring the Variability of Compacted Rmbankments," Hirhway Research Board Record No. 290, pp 23-34.

24. Kennedy, T.W., Hudson, W.R. and IcCullough, B.F. (1975) "Voriability of Material Properties for Airport Pavement Systems," U.S. Army Engineer Waterways Fxperiment Station, Contract Report $\underline{s-75-6}$, Ausust.

25. Lambe, T.i. (1958) "The Structure of Compacted Clay," Joumal of the Soil Mechanics and Foundations Division, ASCE, Vol. 84, No. Sir2.

26. Lumb, P. (1966) "The Variability of Natural Soils," Canadian GeotechnicaI Journal, Vol. III, No. 2, Nay, pp 74-97.

27. Mitchell, J.K. (1955) "Discussion to paper 'Strength Characteristics of Compacted Clays,' by G.A. Leonards," Transactions, ASCE, Vol. 120, pp 14621467.

28. Morse, R.K. (1972) "The Importance of Proper Soil Units for Stitistical Analysis," Proceedinrs of the Pirst Intemational Conference on $A p-$ plications of Statistics and Probability to soil and Structura.I Engineering, Hong Kong Press, pp $347-357$.

29. Peterson, J.I. (1975) "Improviñ Imbankment Design and Performance: Prediction of As-Compacted Field Strength by Laboratory Simulation," Joint Highway Research Project Renort JHRP-75-22, Purdue University, 94 pD 
30. Pettitt, R.A. (1967) "Statistical Analysis of Density Tests," Proceedings, ASCF, Journal of the Hi hivay Division, Vol. 93, No. HW2, November, pp $37-51$.

31. Proctor, R.R. (1933) "Design and Construction of Rolled-Harth Dans," Ingineering News Record, Vol. III: 245-248 (A ugust 31), 286-289 (September 7), 343-351 (September 21), 372-376 (September 28).

32. Road Rescarch Laboratory (1961) Soil Mechanics for Road incineers, Her Majesty's stationary Office,

33. Seed, H.B. and Chan, C.K. (1959) "Structure and Stren th Characteristics of Compacted Clays," Journal of the Soil Mechanics and Foundations Division, ASCE, Vol. 126, Pt. 1, pp 1344-1407.

34. Seed, H.B., Mitchell, J.K. and Chan, C.K. (1960) "The Strength of Compacted Cohesive Soils," Proceedincs, ASCP, Research Conference on Shear Streneth of Cohesive Soils, Boulder, pp 877-964

35. Seed, M.P., and Monismith, C.I. (1954) "Relationship Between Density and Stability of Subgrade Soils," Hirhway Research Board Bulletin No. 93, pp 16-32.

36. Sherman, G.B., Watkins, R.O. and Prysock, R.H. (1967) "A Statistical Analysis of Emoankment Compaction," Hichway Research Board, Highway Research Record, No. 177.

37. Sloane, R.I. and Kell, T.R. (1966) "The Fabric of Nechanically Compacted Kaolin," Clays and Clay Minerals, No. 14.

38. Smart, P. (1969) "Soil Structure in the Electron Microscope," Procecdinss, International Conference of Stmucture, Solid iechanics and Finineering Desien with Civil Fingineerinr laterials, Paper 21, University of Southampton, ingland.

39. Smith, T.W. and Prystock, R.H. (1966) "Discusaion to paper 'Quality Control of Comp cted Earthwork' by Tumbull, W.J., J.R. Compton anà R.G. Ahlvin," Journal of the Soil Irechanics and Foundations Division, ASCE, Vol. 92, No. SM1, September. 
40. Sowers, G.F. and Kennedy, C.M. (1954) "Effect of Reneated Load Applications on Soil Compaction Efficiency," Highway Research Board Bulletin, No. 93, pp 61-64.

41. Sridharan, A., AltschaefIl, A.G. and Diamond, S. (1971) "Pore Size Distribution Studies," Journal of the Soil Mechanics and Foundations Division, ASCE, Vol. 97, No. SM5, May, pp 771787 .

42. Turnbull, W.J., Compton, J.R. and Alnlvin, R.G. (1966) "Quality Control of Compacted Earthwork," Journal of the Soil Mechanics and Foundations Division, ASCP, Vol. 92, Io. SM1, January.

43. Tyman, A.I. and Morris, P.O. (1968) "The Performance of Compaction Plant," Proceedines, Australian Road Research Board, Vol. 4, Part 2, pp 20492100 .

44. U.S. Army Engineer Watemays Experiment Station, Corps of Enfineers: Soil Compaction Investigation, Watemays Exneriment Station, Technical Memorandum 3-271, Reports No. 2 and No. 3, Vicksburg, Miss.

45. Wahls, H.E., Fischer, C.P. and Langfelder, I.J. (1966) "The Compaction of Soil and Rock Thaterials for Highway Purposes," Renort No. FH:VA-RD-73-8, Federal Highway Administration Offices of Research and Development, August, p 205.

46. Ward, W.H., Samuels, S.G. and Butler, M.E. (1959) "Further Studies of the Properties of Iondon Clay," Geotechnique, Vol. 9, No. 2, pp 33-58.

47. Williamson, T.G. (1969) "Embankment Compaction Variability - Control Techniques and Statistical Implications," Highway Research Record, Highway Research Board, ITo. 290.

48. Wilson, S.D. (1950) "Comparative Investigation of a Miniature Compaction Test with Field Compaction," Prescnted before the Annual Meeting, American Society of Civil Engineers, January. 


\section{NOTICE}

The following Appendix listed in the Table of Contents of this Report has not been included in this copy of the Report.

\section{Title}

Appendix

Experimental Data

Pages

$101-108$

A recipient of the Report may secure a copy of the Appendix upon request to:

Joint Highway Research Project

Civil Engineering Building

Purdue University

West Lafayette, Indiana 47907 

